Supporting Information for

\title{
Real-time Imaging of Intracellular Glutathione Levels Based on a Ratiometric Fluorescent Probe with Extremely Fast Response
}

Ming Tian a , Xing-Yu Liu ${ }^{\text {a }}$, Huan He ${ }^{a}$, Xian-Zheng Ma ${ }^{\text {, }}$, Chao Liang b , Yi Liu a,c,d and Feng-Lei Jiang a, ${ }^{*}$

a Sauvage Center for Molecular Sciences, College of Chemistry and Molecular Sciences, Wuhan University, Wuhan 430072, P. R. China

${ }^{\mathrm{b}}$ National Engineering Research Center for Multimedia Software (NERCMS), School of Computer Science, Wuhan University, Wuhan 430072, P. R. China

c Hubei Province Key Laboratory for Coal Conversion and New Carbon Materials, School of Chemistry and Chemical Engineering, Wuhan University of Science and Technology, Wuhan 430081, P. R. China

${ }^{\mathrm{d}}$ Guangxi Key Laboratory of Natural Polymer Chemistry, College of Chemistry and Materials Science, Nanning Normal University, Nanning 530001, P. R. China

*Corresponding Author. E-mail: fljiang@whu.edu.cn. Tel: +86-27-68756667.

\section{Table of Contents}

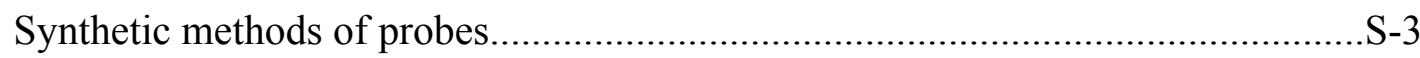

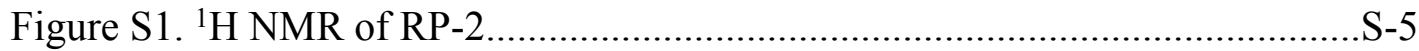

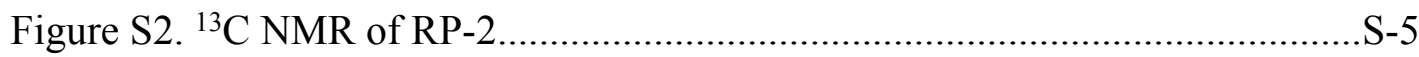

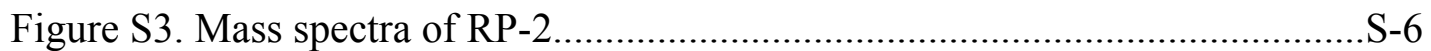

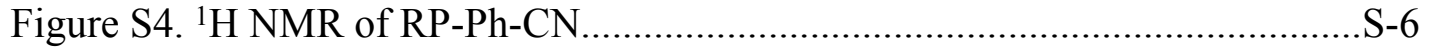

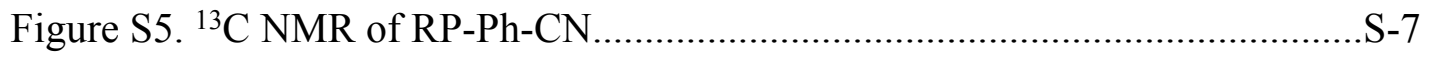

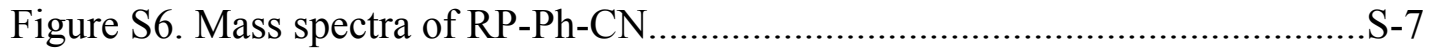

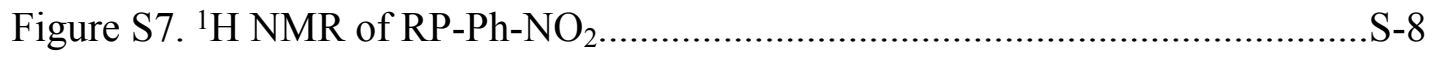




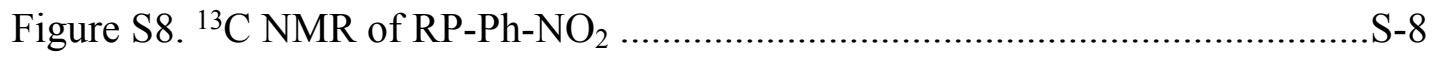

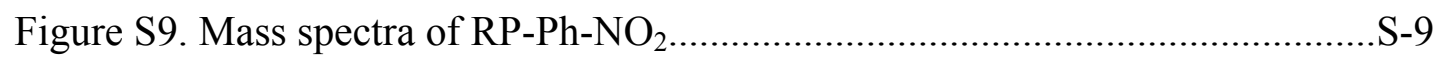

Figure S10. ${ }^{1} \mathrm{H}$ NMR of RP-Ph-OH.................................................................

Figure S11. ${ }^{13} \mathrm{C}$ NMR of RP-Ph-OH................................................................

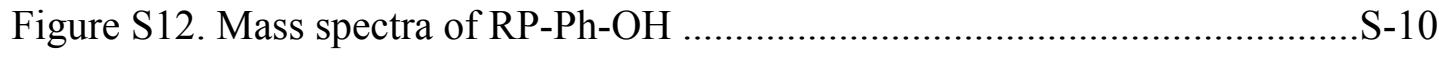

Figure S13. ${ }^{1} \mathrm{H}$ NMR of RP-CN...................................................................

Figure S14. ${ }^{13} \mathrm{C}$ NMR of RP-CN..................................................................

Figure S15. Mass spectra of RP-CN..............................................................

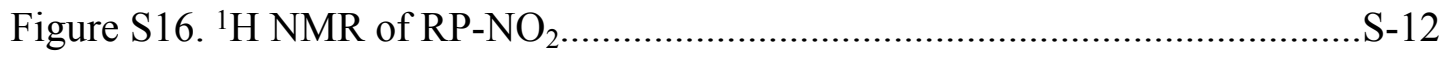

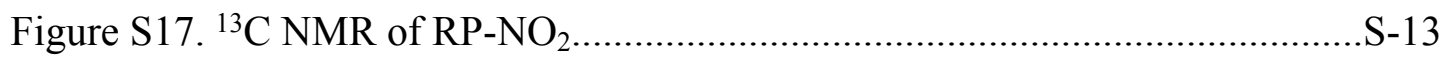

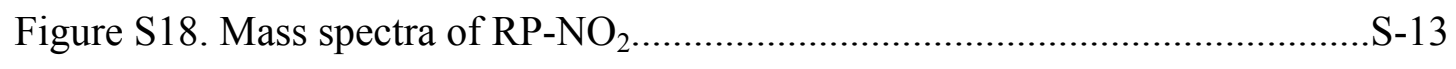

Table S1. Computational geometries and data........................................................ 13

Figure S19. The photo of RP-2 reaction with different amino acids........................S-34

Figure S20. The ESI-MS of adduct, RP-2-GSH......................................................S-34

Figure S21. Fluorescence titration of RP-2 reaction with GSH................................S-35

Figure S22. ITC titration curves of NEM into GSH................................................S-36

Figure S23. The fitting curve by ITC..................................................................

Figure S24. The effects of $\mathrm{pH}$ and viscosity.................................................. -37

Figure S25. Flow cytometric analysis of HeLa cells stained with RP-2 ..................S-37

Table S2. The codes designed in MATLAB...........................................................

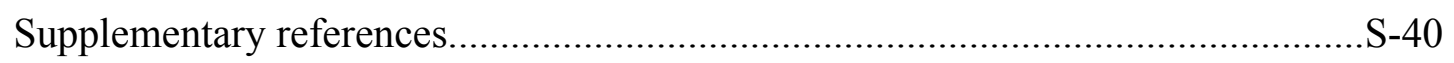


Synthetic Methods. 1a and $1 \mathrm{~b}$ were synthesized according to the literatures. ${ }^{1,2}$

Synthesis of RP-2, RP-Ph-CN, RP-Ph-NO $\mathbf{N}_{2}$ RP-Ph-OH. According to the literature,$^{3} \quad 1 \mathrm{~b} \quad(0.1 \mathrm{mM})$ and cyanoacetamide, 4-acetylbenzonitrile, 4-nitroacetophenone or 2-hydroxyacetophenone $(0.18 \mathrm{mM})$ were dissolved in the mixture of dichloromethane/ethanol $(1: 1, \mathrm{v} / \mathrm{v}, 4 \mathrm{~mL})$, then 2 drops of pyrrolidine were added under stirring. The solution was stirred overnight at room temperature under nitrogen. After the reaction was complete, the solvent was evaporated under reduced pressure. Moreover, recrystallization was performed in the ethanol or dichloromethane for purification to give a solid of RP-2, RP-Ph-CN, RP-Ph- $\mathrm{NO}_{2}$ or $\mathrm{RP}-\mathrm{Ph}-\mathrm{OH}$.

RP-2: ${ }^{1} \mathrm{H}$ NMR (400 MHz, DMSO): $\delta 8.52(\mathrm{~s}, 1 \mathrm{H}), 8.11(\mathrm{~s}, 1 \mathrm{H}), 7.76-7.63(\mathrm{~d}, 2 \mathrm{H})$, $7.12(\mathrm{~s}, 1 \mathrm{H}), 3.39-3.36(\mathrm{~m}, 4 \mathrm{H}), 2.73-2.70(\mathrm{t}, 4 \mathrm{H}), 1.90-1.87(\mathrm{dd}, 4 \mathrm{H}) .{ }^{13} \mathrm{C}$ NMR $(100$ MHz, DMSO): $\delta 163.38,160.92,152.44,149.30,144.69,143.38,127.99,120.40$, 117.77, 108.90, 108.03, 105.76, 101.92, 50.27, 49.70, 27.02, 20.89, 19.92, 19.85 ppm. ESI-MS: $m / z$ calcd for $\mathrm{C}_{19} \mathrm{H}_{17} \mathrm{~N}_{3} \mathrm{O}_{3}[\mathrm{M}+\mathrm{H}]^{+}:$336.1343. Found: 336.1344.

RP-Ph-CN: ${ }^{1} \mathrm{H}$ NMR (400 MHz, $\mathrm{CDCl}_{3}$ ): $\delta$ 8.18-8.13 (dd, 3H), 7.80-7.78 (d, 2H), 7.72-7.66 (m, 2H), $6.94(\mathrm{~s}, 1 \mathrm{H}), 3.37-3.33(\mathrm{dd}, 4 \mathrm{H}), 2.93-2.90(\mathrm{t}, 2 \mathrm{H}), 2.79-2.76(\mathrm{t}$, 2H), 2.01-1.96 (dd, 4H). ${ }^{13} \mathrm{C}$ NMR $\left(100 \mathrm{MHz}, \mathrm{CDCl}_{3}\right): \delta 189.41,160.51,151.80$, $147.95,147.48,142.17,141.94,132.41,128.96,126.30,120.97,119.43,118.33$, 115.52, 113.19, 108.85, 105.99, 50.33, 49.89, 27.47, 21.20, 20.24, 20.14 ppm. ESI-MS: $m / z$ calcd for $\mathrm{C}_{25} \mathrm{H}_{20} \mathrm{~N}_{2} \mathrm{O}_{3}[\mathrm{M}+\mathrm{H}]^{+}:$397.1547. Found: 397.1548.

RP-Ph-NO ${ }_{2}:{ }^{1} \mathrm{H}$ NMR (400 MHz, $\left.\mathrm{CDCl}_{3}\right): \delta 8.34-8.32(\mathrm{~d}, 2 \mathrm{H}), 8.22-8.16$ (dd, 3H), 7.73-7.68 (m, 2H), $6.94(\mathrm{~s}, 1 \mathrm{H}), 3.37-3.33(\mathrm{dd}, 4 \mathrm{H}), 2.93-2.90(\mathrm{t}, 2 \mathrm{H}), 2.80-2.77(\mathrm{t}$, 2H), 2.01-1.99 (m, 4H). ${ }^{13} \mathrm{C}$ NMR (100 MHz, $\left.\mathrm{CDCl}_{3}\right): \delta$ 189.20, 160.50, 151.81, $149.89,148.00,147.56,143.52,142.36,129.49,126.32,123.71,121.03,119.45$, 113.11, 108.86, 105.98, 50.29, 49.89, 27.46, 21.17, 20.21, 20.11 ppm. ESI-MS: $\mathrm{m} / \mathrm{z}$ calcd for $\mathrm{C}_{24} \mathrm{H}_{20} \mathrm{~N}_{2} \mathrm{O}_{5}[\mathrm{M}+\mathrm{H}]^{+}$: 417.1445. Found: 417.1448 .

RP-Ph-OH: ${ }^{1} \mathrm{H}$ NMR (400 MHz, $\left.\mathrm{CDCl}_{3}\right): \delta 13.11(\mathrm{~s}, 1 \mathrm{H}), 8.34-8.30(\mathrm{~d}, 1 \mathrm{H})$, 8.03-8.01 (d, 1H), 7.72-7.68 (t, 2H), 7.49-7.45 (t, 1H), 7.01-6.93 (m, 3H), 3.35-3.32 (t, 
4H), 2.93-2.89 (t, 2H), 2.78-2.75 (t, 2H), 2.00-1.96 (dd, 4H). ${ }^{13} \mathrm{C}$ NMR (100 MHz, $\left.\mathrm{CDCl}_{3}\right): \delta 194.48,163.48,160.48,151.73,147.79,147.30,141.26,135.99,130.19$, 126.23, 120.46, 120.35, 119.33, 118.80, 118.24, 113.39, 108.84, 105.96, 50.24, 49.85, 27.44, 21.18, 20.23, 20.12 ppm. ESI-MS: $m / z$ calcd for $\mathrm{C}_{24} \mathrm{H}_{21} \mathrm{NO}_{4}[\mathrm{M}+\mathrm{H}]^{+}$: 388.1543. Found: 388.1535.

Synthesis of RP-CN. RP-CN was synthesized according to the literature. ${ }^{4}$ To a solution of $1 \mathrm{~b}(0.2 \mathrm{mM})$ and malononitrile $(0.4 \mathrm{mM})$ in ethanol was added 3 drops of piperidine with stirring under nitrogen. The resulting solution was stirred overnight at room temperature, then the solvent was evaporated under reduced pressure. The crude product was further purified by recrystallization in the mixture of ethanol and dichloromethane to afford a solid of RP-CN.

RP-CN: ${ }^{1} \mathrm{H}$ NMR (400 MHz, $\left.\mathrm{CDCl}_{3}\right): \delta 8.64(\mathrm{~s}, 1 \mathrm{H}), 8.04(\mathrm{~s}, 1 \mathrm{H}), 7.01(\mathrm{~s}, 1 \mathrm{H})$, 3.46-3.42 (dd, 4H), 2.89-2.85 (t, 2H), 2.79-2.76 (t, 2H), 2.04-1.99 (dd, 4H). ${ }^{13} \mathrm{C}$ NMR $\left(100 \mathrm{MHz}, \mathrm{CDCl}_{3}\right): \delta 160.66,153.27,152.39,150.69,143.64,128.62,120.81$, $115.07,114.55,108.96,108.73,106.50,74.59$, 50.81, 50.35, 27.21, 20.84, 19.83, 19.71 ppm. ESI-MS: $m / z$ calcd for $\mathrm{C}_{19} \mathrm{H}_{15} \mathrm{~N}_{3} \mathrm{O}_{2}[\mathrm{M}+\mathrm{H}]^{+}:$318.1237. Found: 318.1238 .

Synthesis of RP-NO $\mathbf{O}_{2} .1 \mathrm{~b}(0.1 \mathrm{mM})$ and nitromethane $(0.4 \mathrm{mM})$ were dissolved in methylbenzene $(30 \mathrm{~mL})$ with stirring under nitrogen. Then, a drop of piperidine and glacial acetic acid were added to the mixture. After the solution was heated to reflux for $3 \mathrm{~h}$, methylbenzene was removed under reduced pressure. The crude product was washed with methanol and further purified by column chromatography on silica gel using dichloromethane as eluent to obtain the RP- $\mathrm{NO}_{2}$.

RP-NO ${ }_{2}:{ }^{1} \mathrm{H}$ NMR (400 MHz, $\left.\mathrm{CDCl}_{3}\right): \delta 8.29-8.26(\mathrm{~d}, 1 \mathrm{H}), 7.81-7.78(\mathrm{~d}, 1 \mathrm{H}), 7.69$ $(\mathrm{s}, 1 \mathrm{H}), 6.94(\mathrm{~s}, 1 \mathrm{H}), 3.37-3.34(\mathrm{dd}, 4 \mathrm{H}), 2.91-2.87(\mathrm{t}, 2 \mathrm{H}), 2.79-2.76(\mathrm{t}, 2 \mathrm{H})$, 2.02-1.96 (m, 4H). ${ }^{13} \mathrm{C}$ NMR (100 MHz, $\left.\mathrm{CDCl}_{3}\right): \delta$ 152.18, 148.57, 137.10, 135.22, $126.58,119.70,109.02,108.80,106.03$, 99.98, 50.36, 49.96, 27.42, 21.06, 20.08, 20.01 ppm. ESI-MS: $m / z$ calcd for $\mathrm{C}_{17} \mathrm{H}_{16} \mathrm{~N}_{2} \mathrm{O}_{4}[\mathrm{M}+\mathrm{H}]^{+}:$313.1183. Found: 313.1190 . 


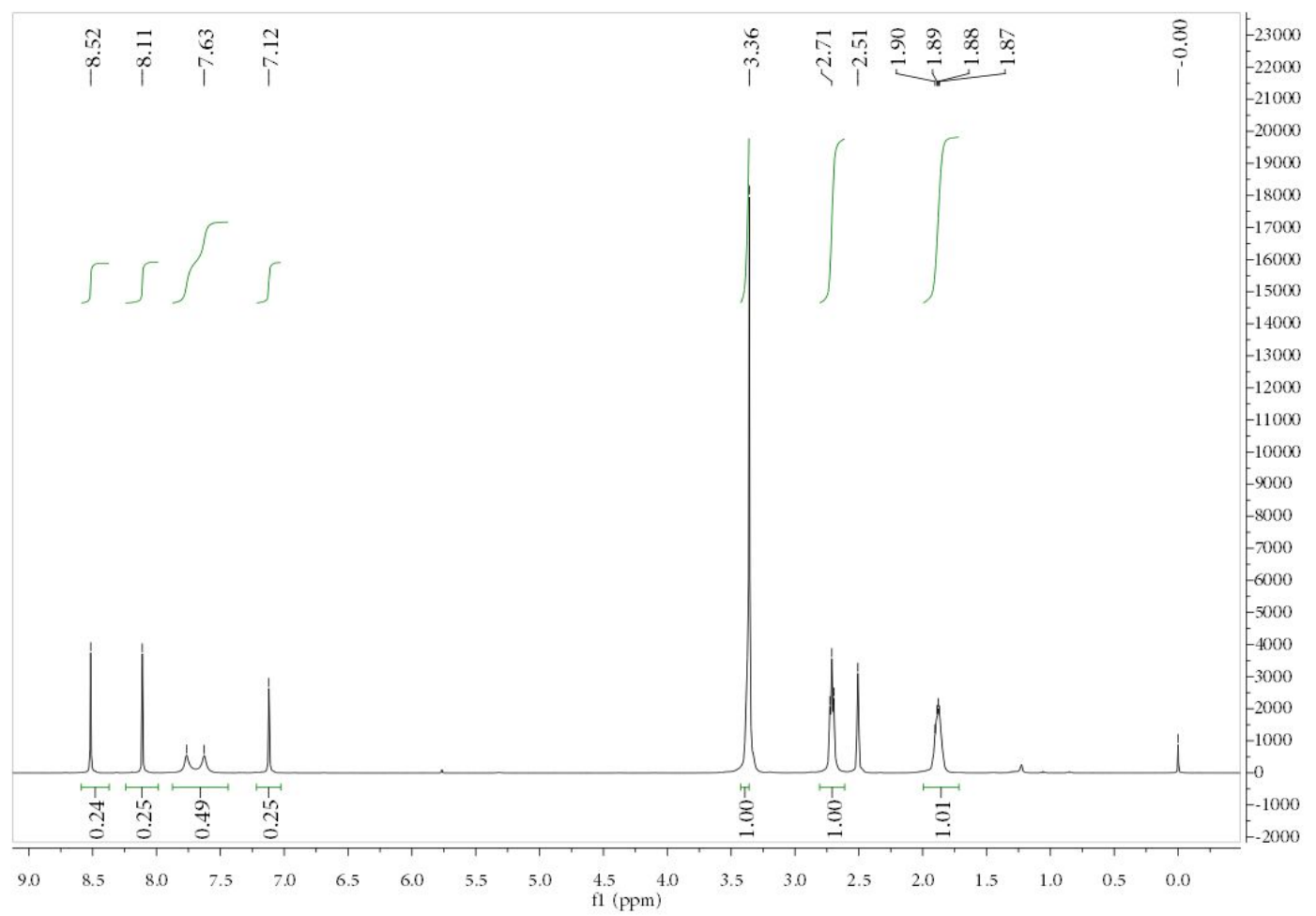

Figure S1. ${ }^{1} \mathrm{H}$ NMR of RP-2.

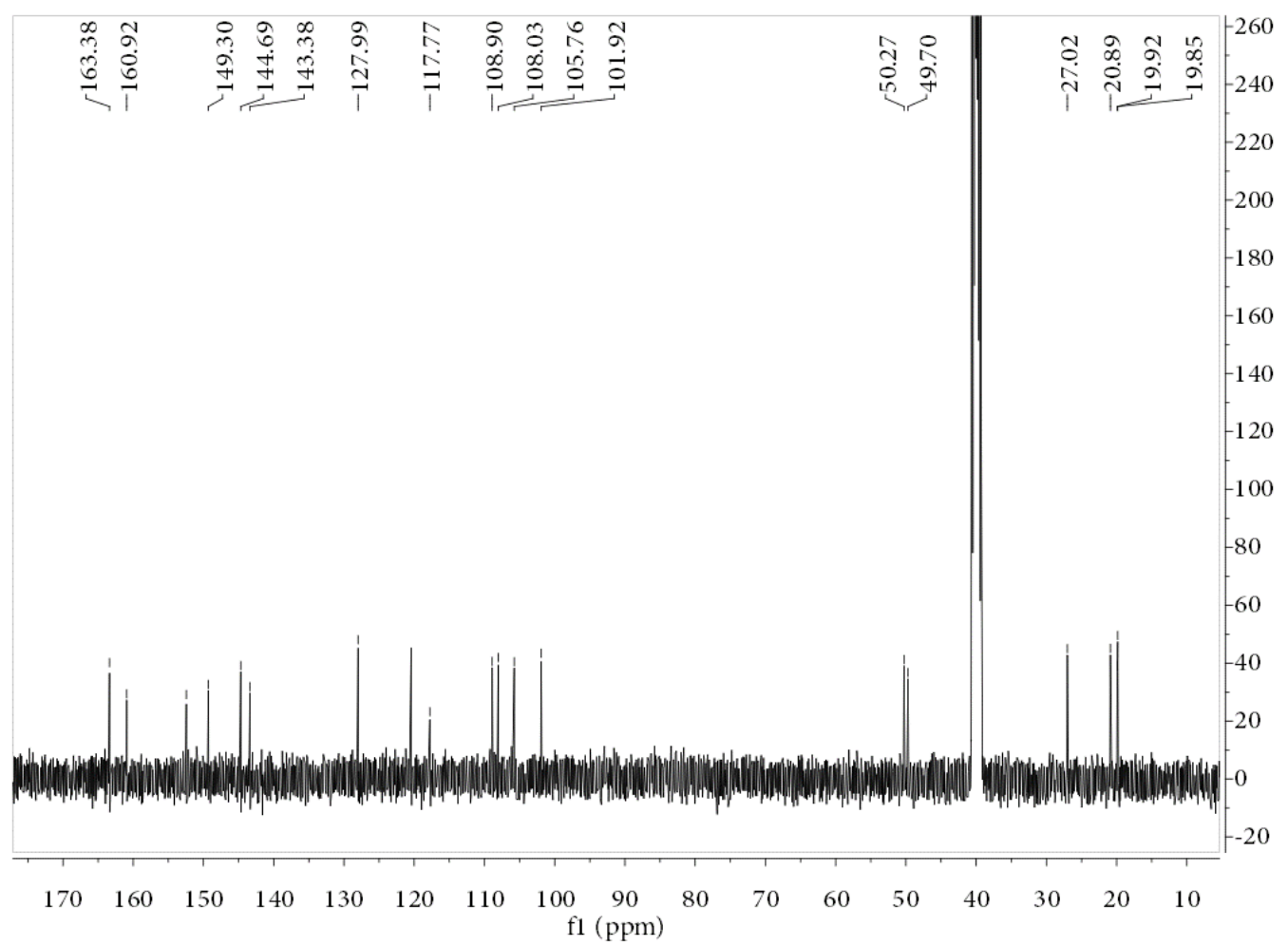

Figure S2. ${ }^{13} \mathrm{C}$ NMR of RP-2. 


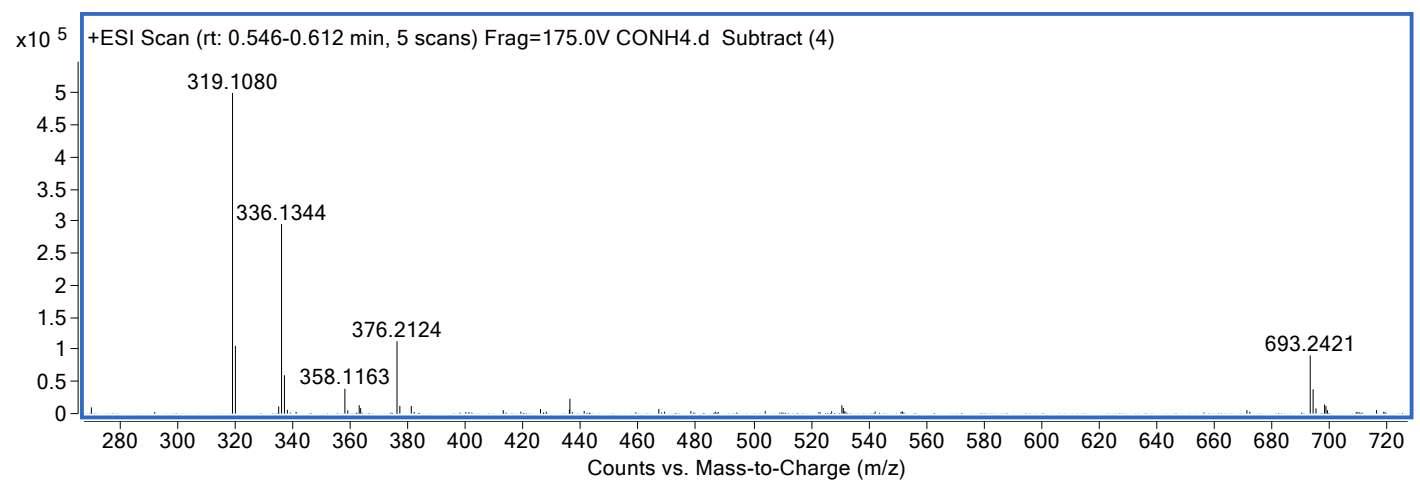

Figure S3. Mass spectra of RP-2.

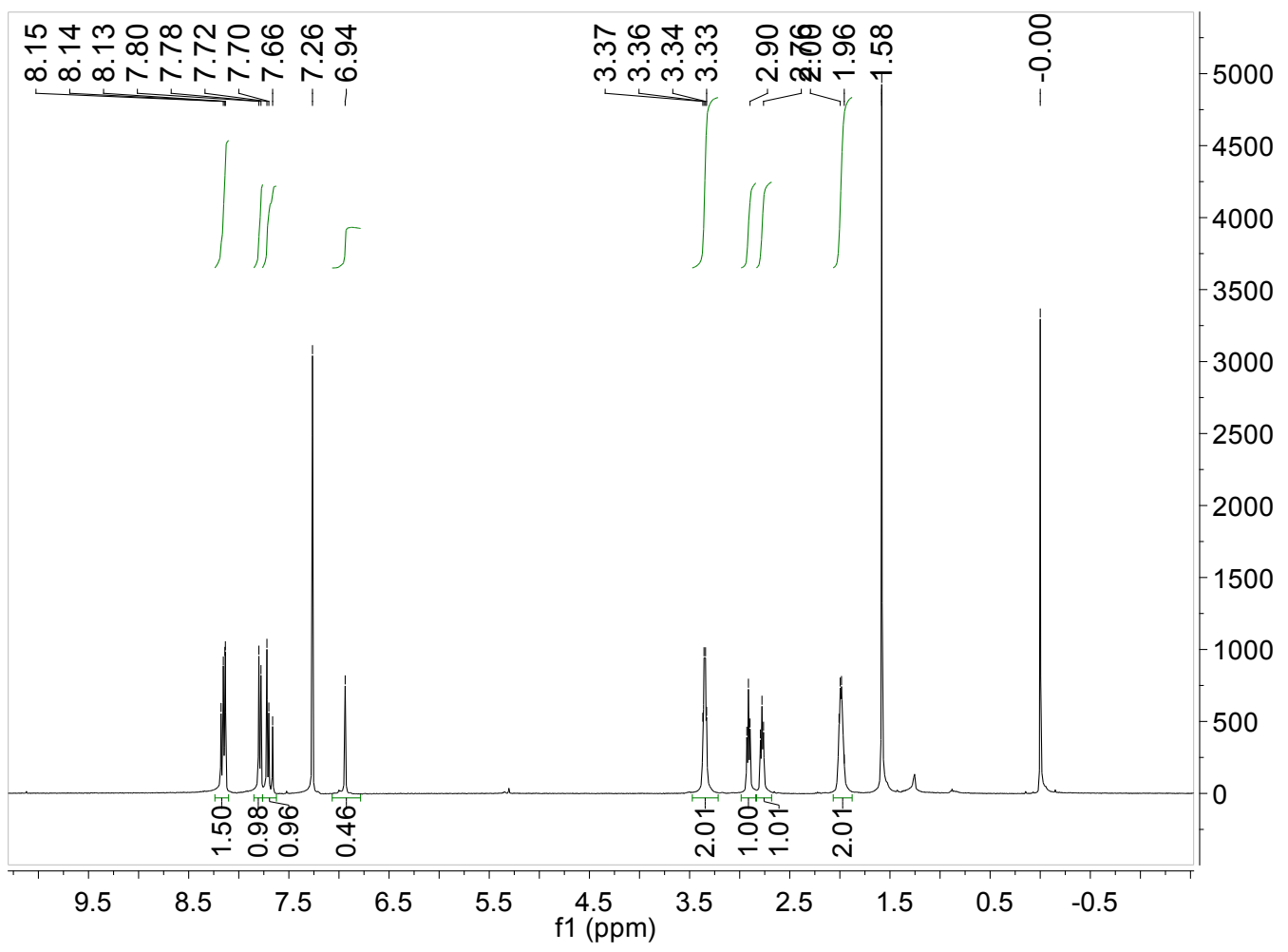

Figure S4. ${ }^{1} \mathrm{H}$ NMR of RP-Ph-CN. 


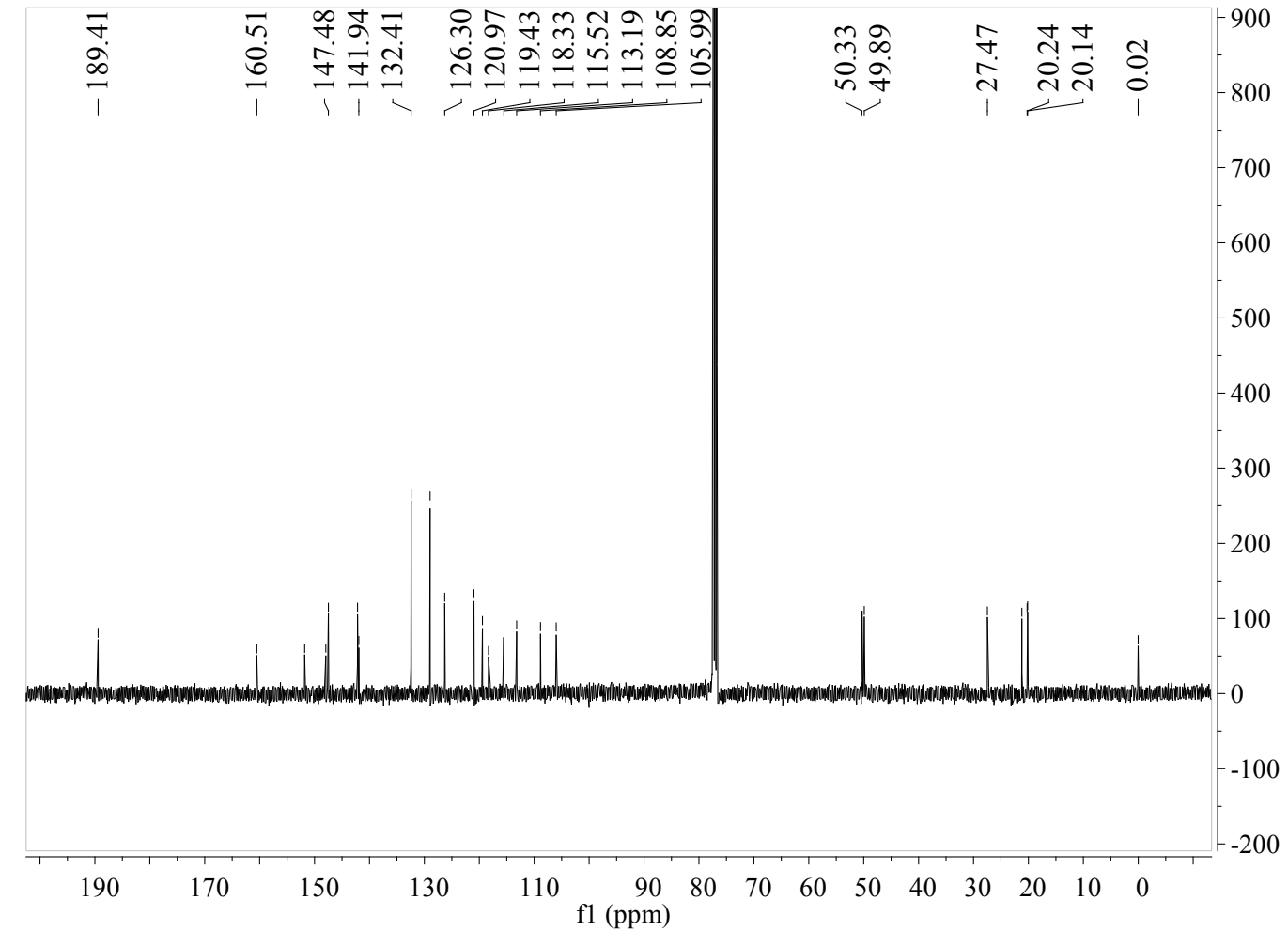

Figure S5. ${ }^{13} \mathrm{C}$ NMR of RP-Ph-CN.

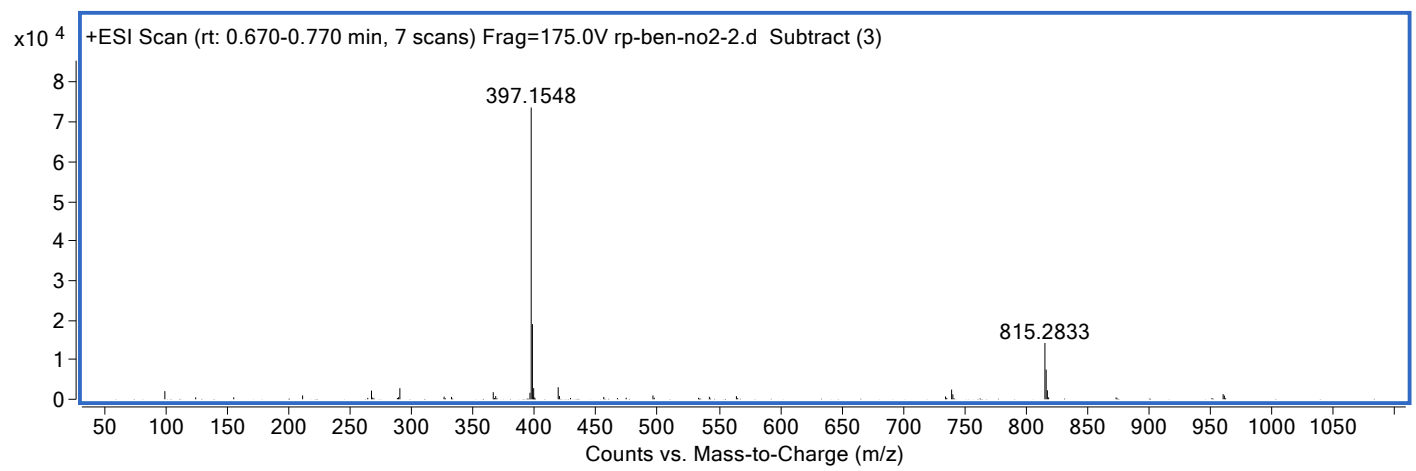

Figure S6. Mass spectra of RP-Ph-CN. 


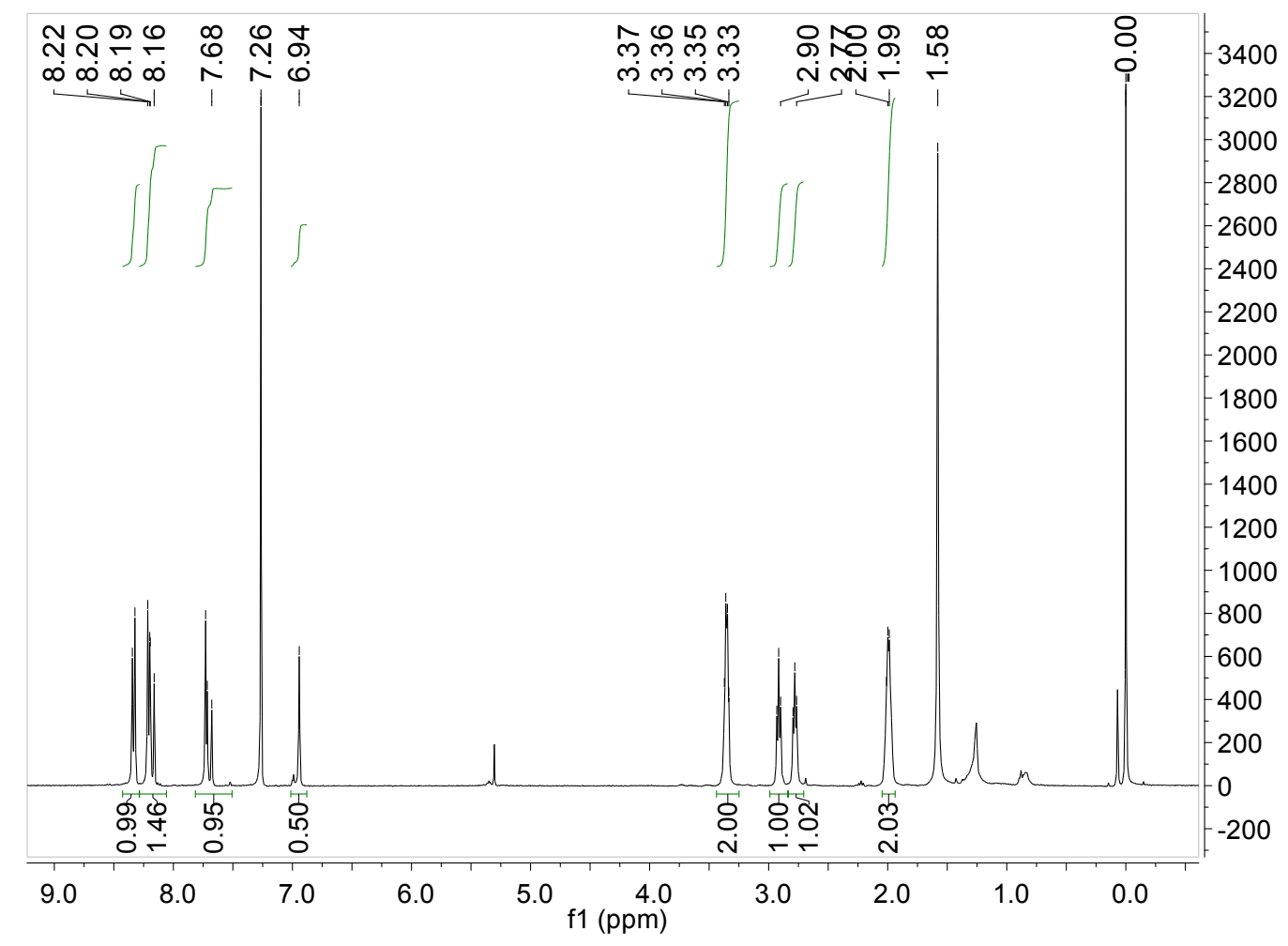

Figure S7. ${ }^{1} \mathrm{H}$ NMR of RP-Ph- $\mathrm{NO}_{2}$.

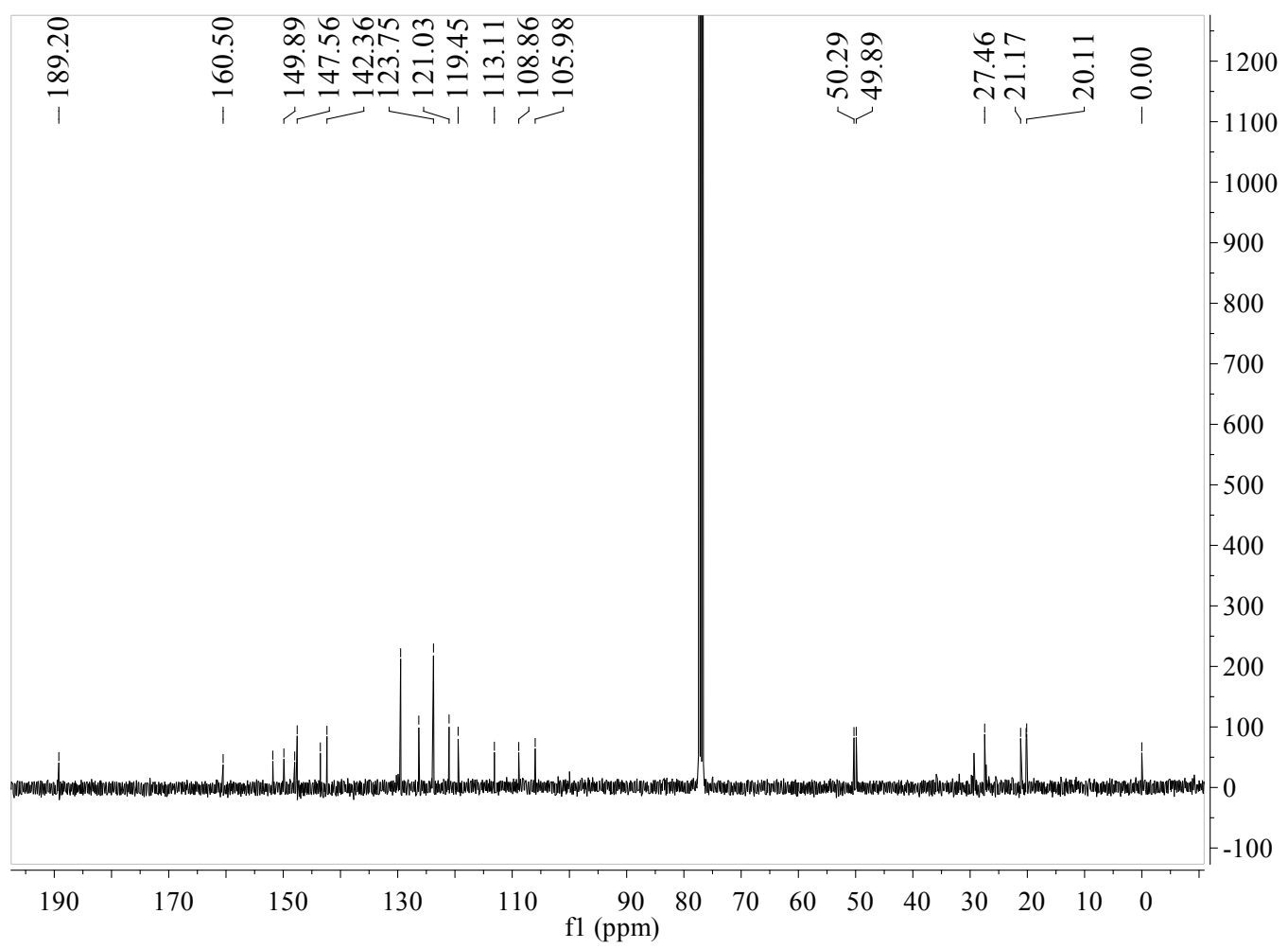

Figure S8. ${ }^{13} \mathrm{C}$ NMR of RP-Ph- $\mathrm{NO}_{2}$. 


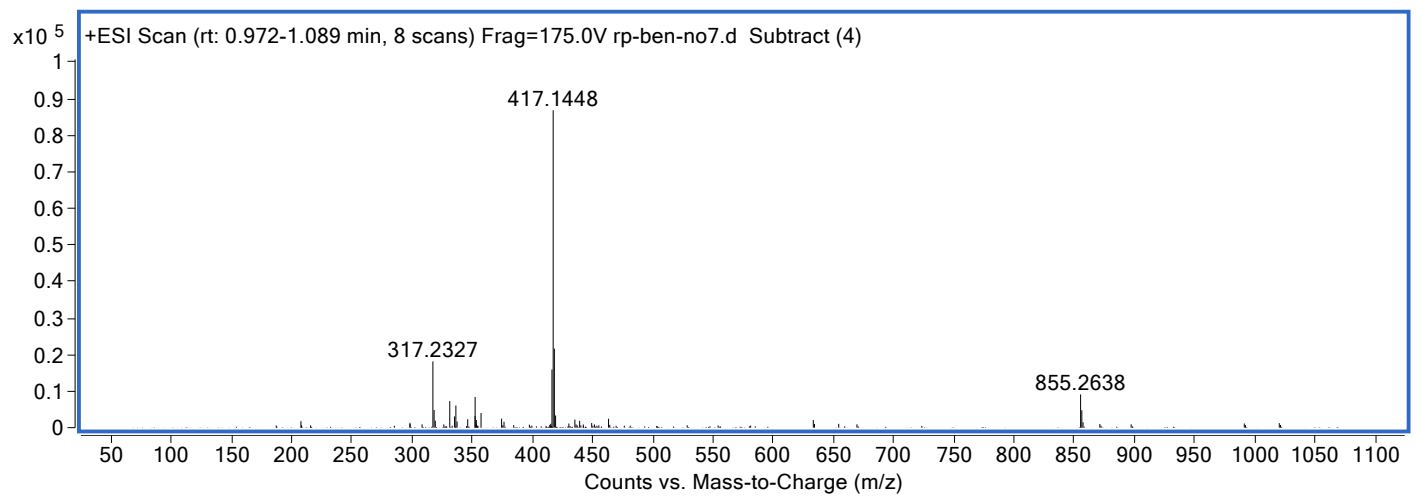

Figure S9. Mass spectra of RP-Ph- $\mathrm{NO}_{2}$.

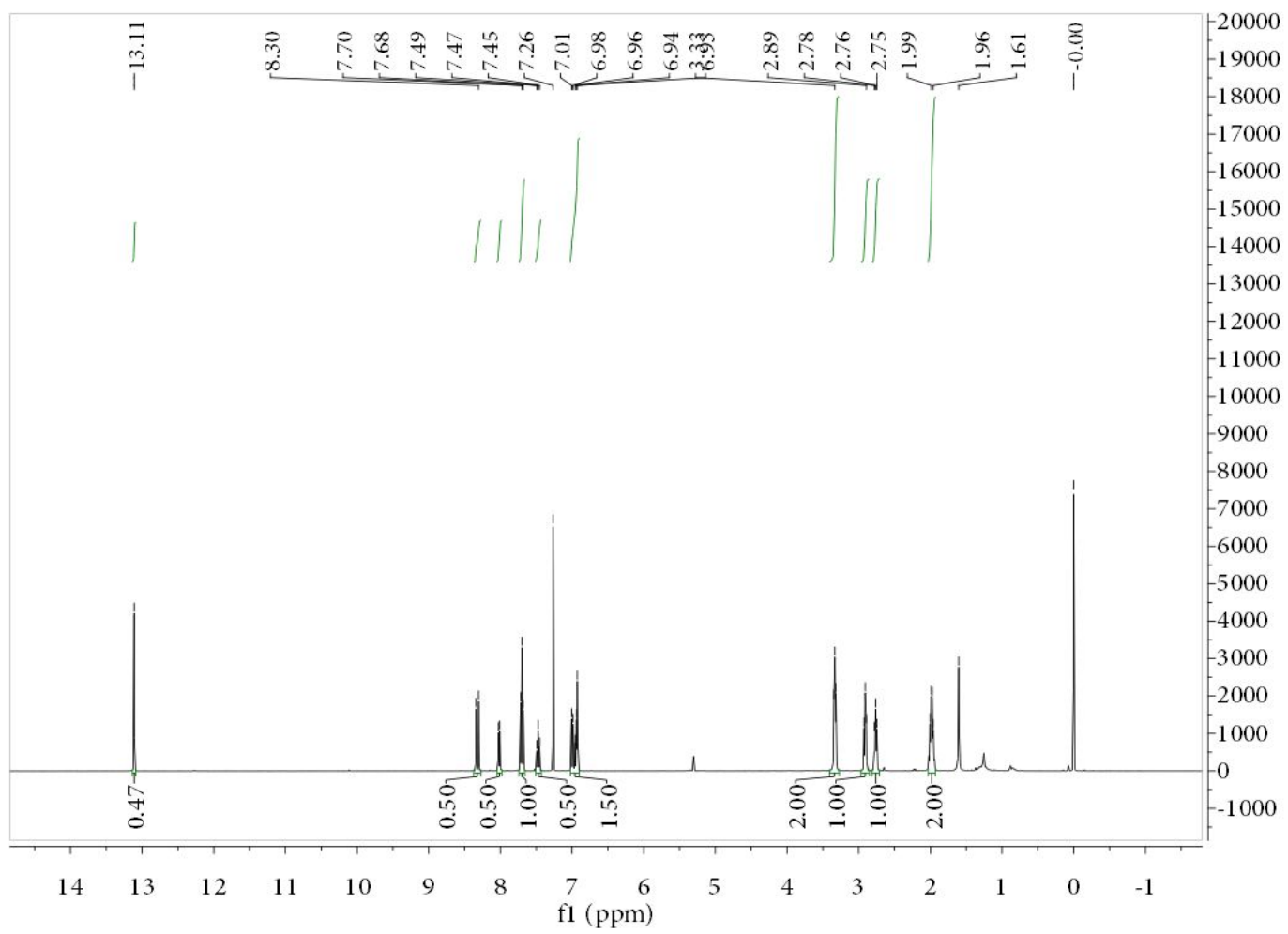

Figure S10. ${ }^{1} \mathrm{H}$ NMR of RP-Ph-OH. 


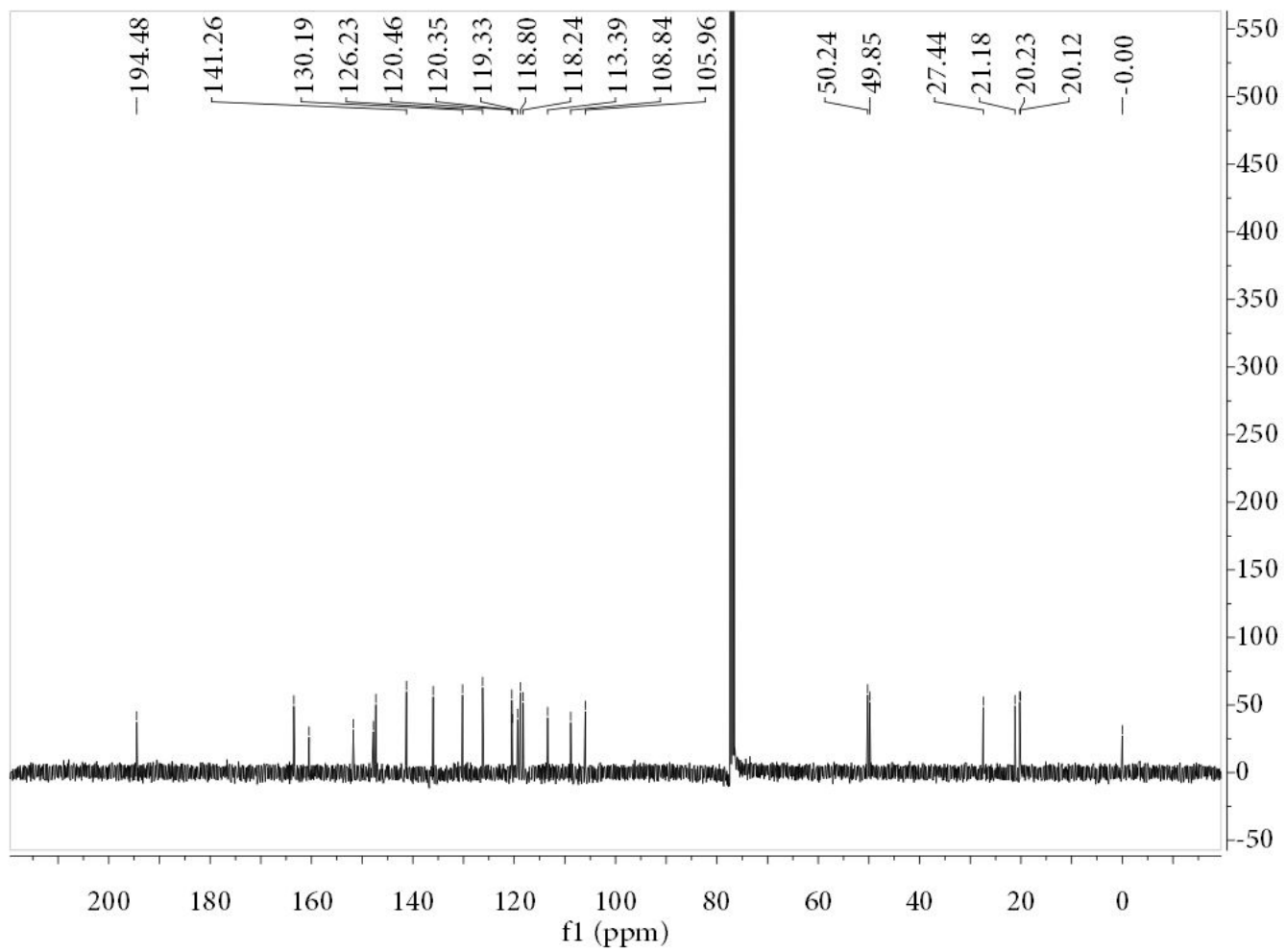

Figure S11. ${ }^{13} \mathrm{C}$ NMR of RP-Ph-OH.

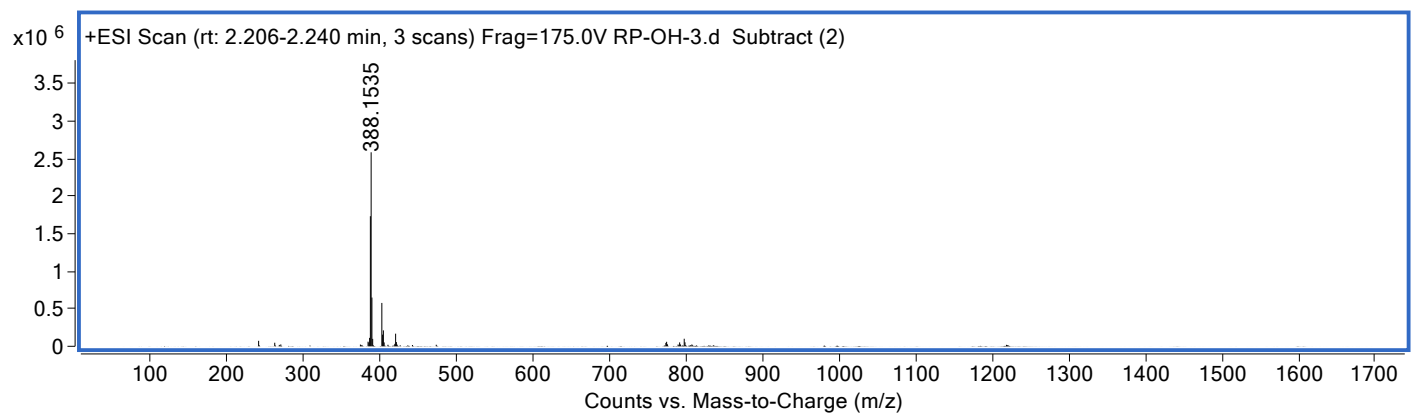

Figure S12. Mass spectra of RP-Ph-OH. 


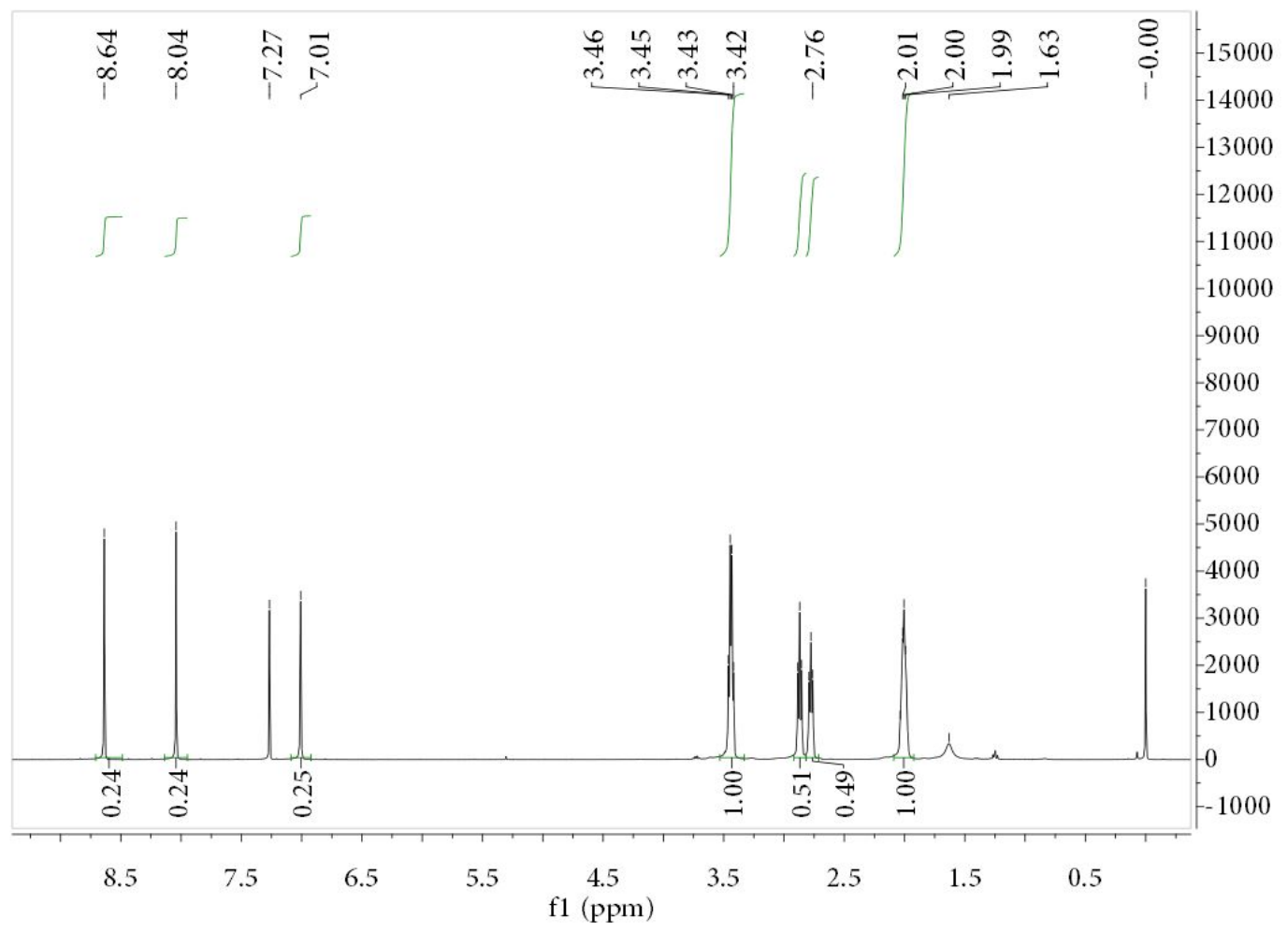

Figure S13. ${ }^{1} \mathrm{H}$ NMR of RP-CN.

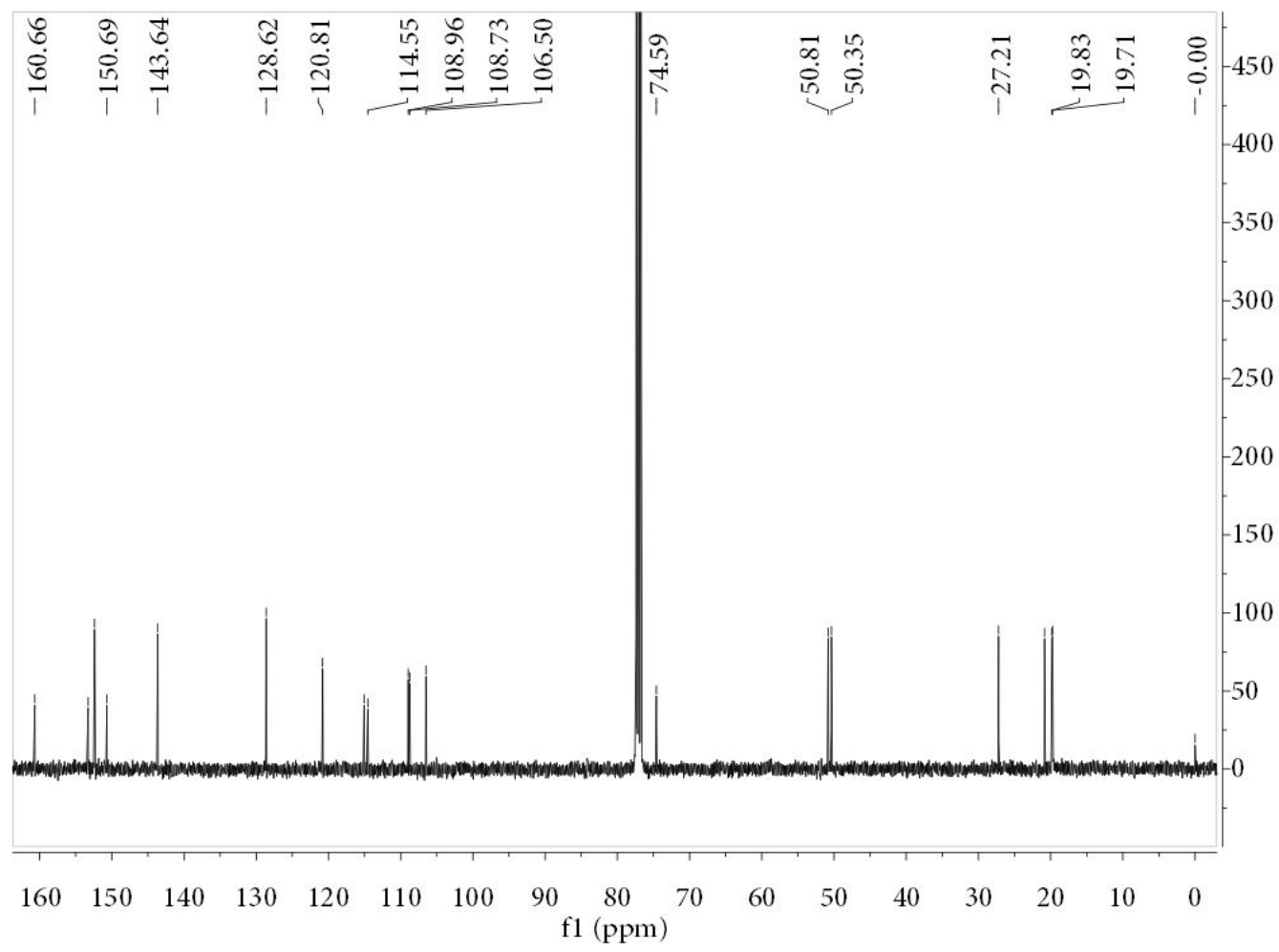

Figure S14. ${ }^{13} \mathrm{C}$ NMR of RP-CN. 


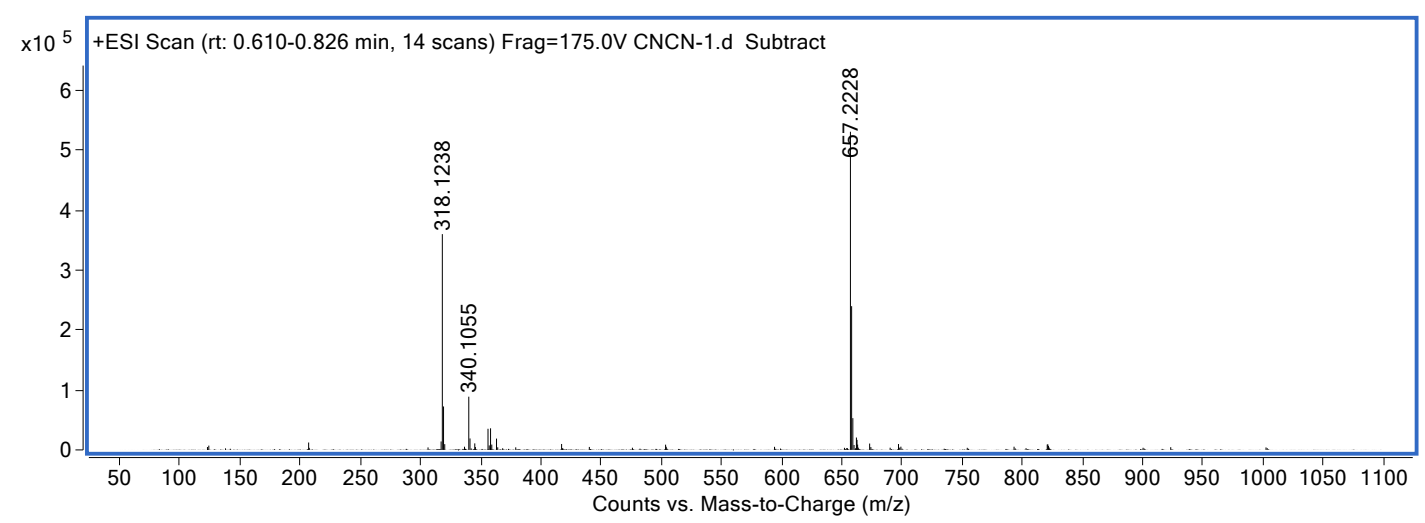

Figure S15. Mass spectra of RP-CN.

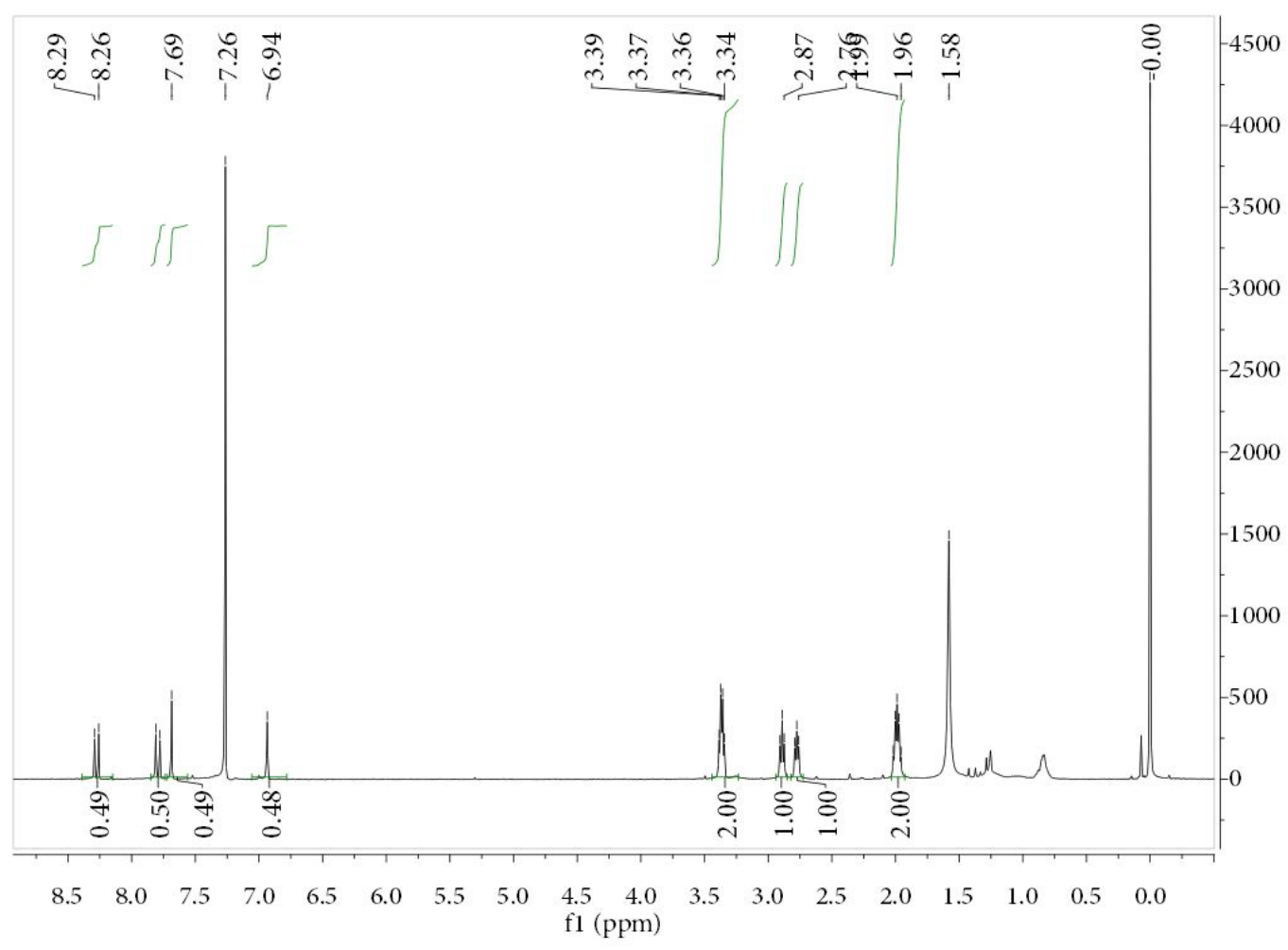

Figure S16. ${ }^{1} \mathrm{H}$ NMR of RP-NO${ }_{2}$. 


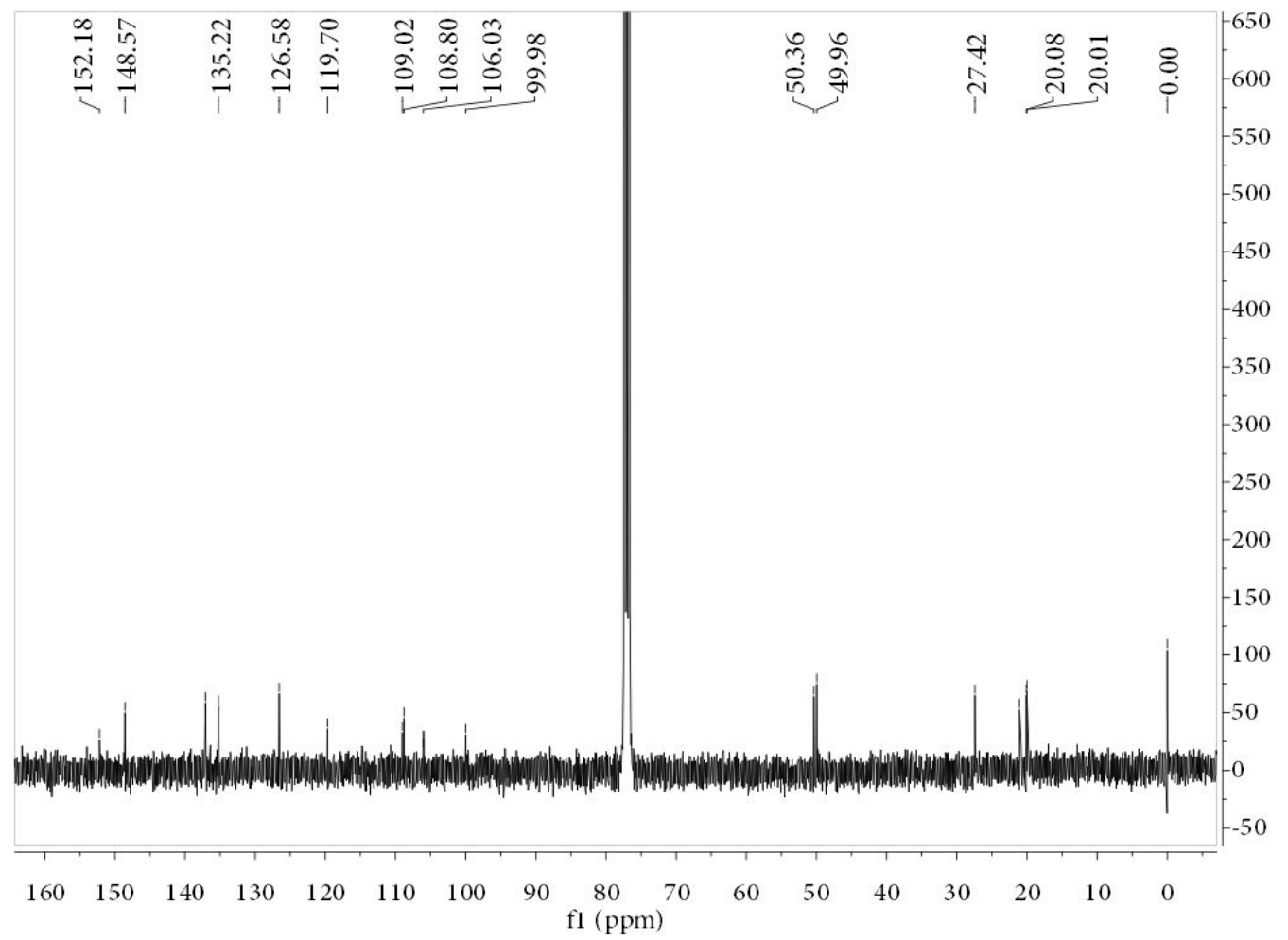

Figure S17. ${ }^{13} \mathrm{C}$ NMR of $\mathrm{RP}-\mathrm{NO}_{2}$.

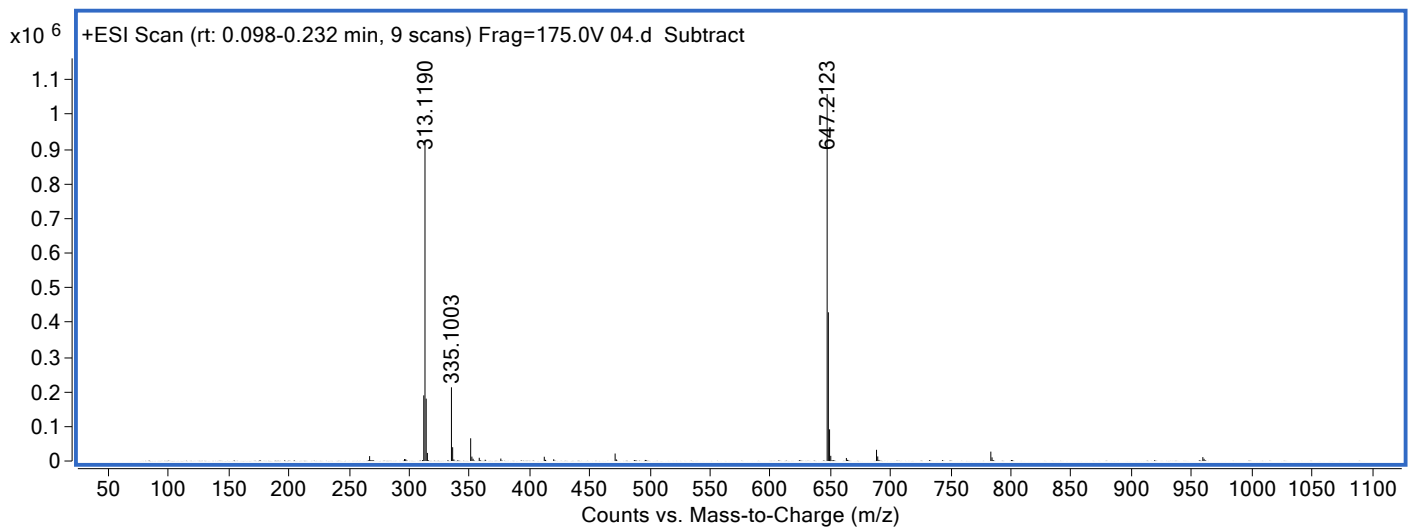

Figure S18. Mass spectra of RP-NO .

Table S1. The geometries listed below were optimized at the M06-2X/6-31G(d) level of theory with the SMD solvation method in water.

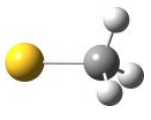

$\mathrm{CH}_{3} \mathrm{~S}^{-}$

Frequencies

734.5783

960.6791

965.3533 
1378.3828

3038.4169

Zero-point correction $=$

(Hartree/Particle)

Thermal correction to Energy=

Thermal correction to Enthalpy=

Thermal correction to Gibbs Free Energy=

Sum of electronic and zero-point Energies=

Sum of electronic and thermal Energies=

Sum of electronic and thermal Enthalpies=

Sum of electronic and thermal Free Energies=
1512.9380

3104.0025

0.037130

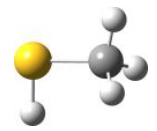

$\mathrm{CH}_{3} \mathrm{SH}$

Frequencies

345.7921

1009.4116

1484.0776

3108.8497

Zero-point correction=

Thermal correction to Energy=

Thermal correction to Enthalpy=

Thermal correction to Gibbs Free Energy=

Sum of electronic and zero-point Energies=

Sum of electronic and thermal Energies=

Sum of electronic and thermal Enthalpies=

Sum of electronic and thermal Free Energies=

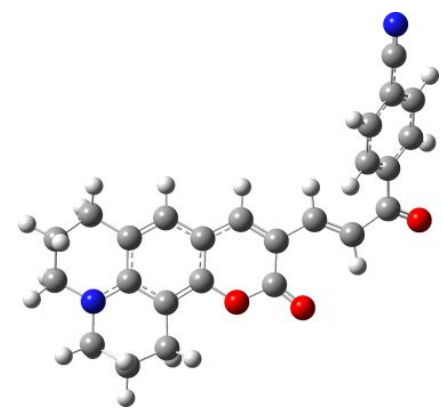

$\mathrm{RP}-\mathrm{Ph}-\mathrm{CN}$

Frequencies

23.4142

29.2633

61.7471

66.9306
821.4211

1398.2615

2730.6641

3209.7518

0.047097 (Hartree/Particle)

0.050543

0.051487

0.023037

$-438.582057$

$-438.578611$

$-438.577667$

$-438.606117$ 


\begin{tabular}{|c|c|c|}
\hline 85.6116 & 101.3398 & 108.2450 \\
\hline 134.5746 & 140.2868 & 158.6578 \\
\hline 177.6846 & 199.5331 & 208.7795 \\
\hline 212.3819 & 235.1651 & 271.5326 \\
\hline 288.3476 & 301.7871 & 327.1754 \\
\hline 339.1126 & 358.9965 & 368.1887 \\
\hline 391.8128 & 402.1386 & 411.3167 \\
\hline 420.1767 & 434.8616 & 444.9764 \\
\hline 463.1840 & 469.5224 & 511.9681 \\
\hline 525.6700 & 530.6538 & 556.8045 \\
\hline 566.0982 & 575.8854 & 583.6913 \\
\hline 608.8365 & 625.1898 & 643.7290 \\
\hline 654.9333 & 672.1562 & 692.6371 \\
\hline 701.5642 & 728.5478 & 740.1775 \\
\hline 750.4174 & 766.8912 & 787.7529 \\
\hline 812.6789 & 829.3198 & 867.2936 \\
\hline 879.8472 & 883.2498 & 885.7110 \\
\hline 896.1669 & 912.7050 & 915.8932 \\
\hline 931.4412 & 938.1594 & 966.0791 \\
\hline 996.8006 & 1001.2348 & 1010.4204 \\
\hline 1018.3749 & 1038.7997 & 1043.2846 \\
\hline 1044.4163 & 1057.8494 & 1081.2222 \\
\hline 1106.1851 & 1110.8384 & 1115.5704 \\
\hline 1126.5209 & 1134.8557 & 1148.5402 \\
\hline 1195.7186 & 1207.0842 & 1212.3239 \\
\hline 1222.2272 & 1236.2556 & 1240.7271 \\
\hline 1241.7933 & 1254.4731 & 1264.2424 \\
\hline 1266.8864 & 1281.3483 & 1319.7649 \\
\hline 1327.9150 & 1330.0685 & 1341.1652 \\
\hline 1349.3221 & 1352.2893 & 1359.5879 \\
\hline 1370.1458 & 1375.6282 & 1385.8677 \\
\hline 1397.3969 & 1405.2177 & 1411.2934 \\
\hline 1428.8287 & 1433.8727 & 1458.8340 \\
\hline 1481.3414 & 1487.1407 & 1489.8182 \\
\hline 1502.2725 & 1503.6162 & 1511.2317 \\
\hline 1522.9527 & 1532.1786 & 1563.3755 \\
\hline 1581.5713 & 1626.4524 & 1652.0886 \\
\hline 1658.8107 & 1686.6316 & 1702.7348 \\
\hline 1704.3023 & 1734.9858 & 1785.4379 \\
\hline 2377.7513 & 3056.8447 & 3059.6701 \\
\hline 3070.0087 & 3076.5482 & 3099.1672 \\
\hline 3103.8867 & 3133.2425 & 3137.9445 \\
\hline 3142.9602 & 3151.7522 & 3155.5408 \\
\hline 3158.2473 & 3209.7169 & 3227.1697 \\
\hline
\end{tabular}


3235.4641

3262.0383

3239.4656

3267.7458

Zero-point correction $=$

Thermal correction to Energy=

Thermal correction to Enthalpy=

Thermal correction to Gibbs Free Energy=

Sum of electronic and zero-point Energies=

Sum of electronic and thermal Energies $=$

Sum of electronic and thermal Enthalpies=

Sum of electronic and thermal Free Energies=

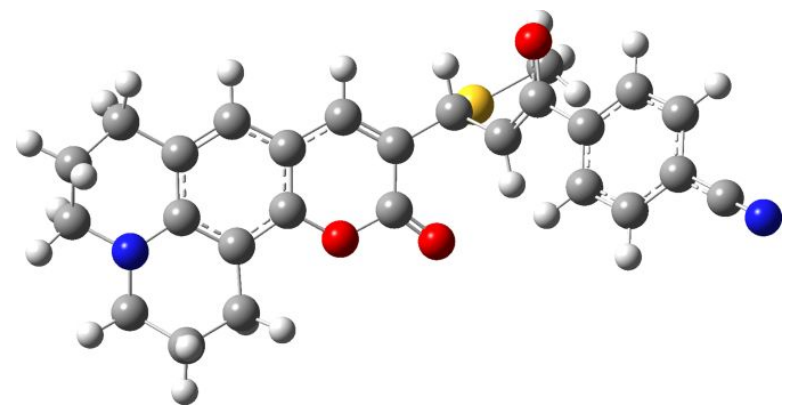

[RP-Ph-CN-SCH$]^{-}$

Frequencies

$\begin{array}{lcc}4.9638 & 16.8634 & 32.8393 \\ 36.9074 & 54.6008 & 59.0362 \\ 75.7723 & 88.7973 & 97.2980 \\ 102.6463 & 113.1983 & 116.1127 \\ 131.4490 & 149.4343 & 165.4573 \\ 175.1379 & 185.0527 & 209.5138 \\ 223.4563 & 228.1599 & 253.9019 \\ 267.5574 & 284.7795 & 286.9826 \\ 310.5316 & 318.7356 & 350.4845 \\ 361.5408 & 391.2695 & 395.6346 \\ 408.7016 & 412.3672 & 431.5799 \\ 436.9380 & 454.5314 & 464.4886 \\ 472.0871 & 511.9798 & 526.2284 \\ 530.8136 & 549.9680 & 562.0684 \\ 572.5548 & 579.1917 & 585.1120 \\ 625.1873 & 643.0040 & 652.8206 \\ 662.4803 & 689.8551 & 699.2213 \\ 702.7534 & 711.8246 & 735.7033 \\ 746.5585 & 756.8839 & 770.1114 \\ 787.1301 & 805.8053 & 812.5058 \\ 864.2250 & 871.1447 & 876.9650 \\ 882.9194 & 888.3840 & 892.7404 \\ 911.3891 & 920.2942 & 929.1236 \\ & & \\ & & 5-16\end{array}$

16.8634

88.7973

113.1983

149.4343

185.0527

318.7356

391.2695

412.3672

454.5314

511.9798

549.9680

689.8551

711.8246

756.8839

805.8053

888.3840

S-16
32.8393

97.2980

116.1127

65.4573

209.5138

253.9019

286.9826

350.4845

395.6346

431.5799

464.4886

526.2284

562.0684

585.1120

652.8206

735.7033

770.1114

812.5058

876.9650

892.7404

929.1236
3250.5371

3271.0886

0.402791 (Hartree/Particle)

0.426788

0.427732

0.347927

$-1298.984653$

$-1298.960657$

$-1298.959713$

$-1299.039517$ 


\begin{tabular}{|c|c|c|}
\hline 961.1821 & 976.2787 & 988.7508 \\
\hline 994.8652 & 1006.2870 & 1012.5766 \\
\hline 1013.6018 & 1035.0488 & 1040.1530 \\
\hline 1051.6784 & 1080.6509 & 1088.9907 \\
\hline 1106.4967 & 1111.3363 & 1120.3160 \\
\hline 1131.2798 & 1136.5939 & 1158.6861 \\
\hline 1190.4279 & 1201.0766 & 1206.0690 \\
\hline 1218.6929 & 1221.4461 & 1232.6895 \\
\hline 1237.5117 & 1241.4109 & 1257.1031 \\
\hline 1258.9560 & 1261.2185 & 1268.8008 \\
\hline 1310.0935 & 1314.1820 & 1323.9116 \\
\hline 1327.6052 & 1333.2583 & 1343.4855 \\
\hline 1348.0659 & 1372.0951 & 1381.2729 \\
\hline 1385.8624 & 1391.8799 & 1398.9282 \\
\hline 1404.1870 & 1414.9125 & 1420.7699 \\
\hline 1446.7538 & 1466.2944 & 1474.3923 \\
\hline 1483.9170 & 1485.0333 & 1490.1507 \\
\hline 1496.3092 & 1500.2013 & 1506.1408 \\
\hline 1514.4165 & 1517.0651 & 1524.6303 \\
\hline 1554.2775 & 1566.2706 & 1614.3122 \\
\hline 1645.5313 & 1653.2315 & 1682.9370 \\
\hline 1691.8493 & 1710.5867 & 1776.8058 \\
\hline 2361.1968 & 3032.9921 & 3038.8024 \\
\hline 3073.4317 & 3073.9638 & 3088.5175 \\
\hline 3093.7613 & 3096.4760 & 3129.6130 \\
\hline 3130.1329 & 3136.0477 & 3140.8729 \\
\hline 3142.4660 & 3149.8176 & 3151.3667 \\
\hline 3181.8133 & 3186.8138 & 3205.2498 \\
\hline 3213.1718 & 3233.8014 & 3235.8532 \\
\hline 3253.3618 & 3262.3669 & 3271.4597 \\
\hline \multicolumn{2}{|c|}{ Zero-point correction $=$} & 0.441488 (Hartree/Particle) \\
\hline \multicolumn{2}{|c|}{ Thermal correction to Energy= } & 0.469097 \\
\hline \multicolumn{2}{|c|}{ Thermal correction to Enthalpy= } & 0.470042 \\
\hline \multicolumn{2}{|c|}{ Thermal correction to Gibbs Free Energy= } & 0.380106 \\
\hline \multicolumn{2}{|c|}{ Sum of electronic and zero-point Energies $=$} & -1737.114675 \\
\hline \multicolumn{2}{|c|}{ Sum of electronic and thermal Energies $=$} & -1737.087065 \\
\hline \multicolumn{2}{|c|}{ Sum of electronic and thermal Enthalpies $=$} & -1737.086121 \\
\hline \multicolumn{2}{|c|}{ Sum of electronic and thermal Free Energies $=$} & -1737.176057 \\
\hline
\end{tabular}




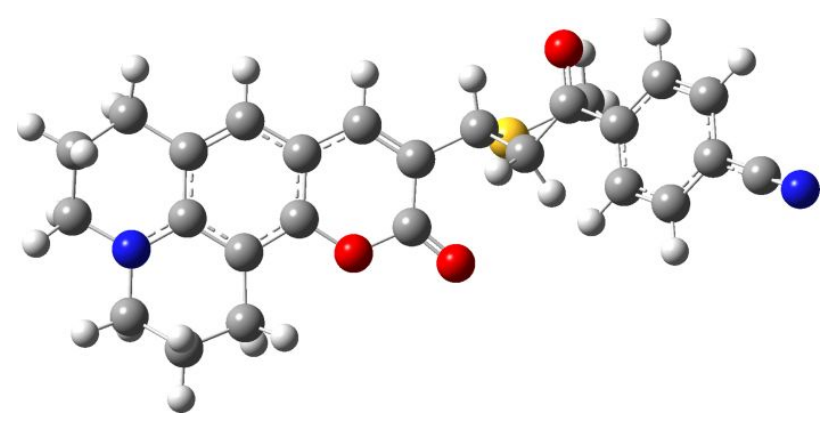

RP-Ph-CN-SCH 3

Frequencies

7.5254

30.1295

79.4935

104.1647

129.5142

170.3616

219.6717

284.5824

314.3428

369.1380

403.9288

439.6753

473.4860

531.6470

565.7143

589.1058

655.9685

708.5313

746.9359

801.3900

863.9912

880.7243

928.9772

967.9586

996.5181

1018.9788

1046.9400

1105.0225

1126.1265

1193.3500

1210.7277

1238.2479

1254.9469
24.4635

46.9985

85.2158

108.0539

158.1434

182.0649

240.2516

285.5097

329.5527

383.4139

413.4554

447.0479

503.7195

549.3056

578.5923

628.7804

683.6350

734.2721

764.3783

813.1245

873.6660

897.8293

931.1726

984.5548

1005.3986

1023.5559

1054.4853

1110.4879

1134.3786

1196.4408

1220.8504

1247.3920

1260.7132
27.0460

64.7872

91.6879

119.5561

164.1966

205.6212

254.0622

293.5598

349.2919

402.7058

419.3915

460.7056

522.8531

559.6458

585.0174

643.0061

699.5257

741.2157

786.2461

856.0654

877.4798

917.6661

956.3906

995.0950

1012.6462

1042.3745

1081.6112

1111.8247

1151.7682

1206.6769

1230.5722

1248.2718

1268.5635 


$\begin{array}{ll}1287.4265 & 1317.9007 \\ 1327.8346 & 1337.4868 \\ 1353.4550 & 1354.9915 \\ 1387.3630 & 1387.8598 \\ 1401.8990 & 1406.0569 \\ 1419.7667 & 1427.3736 \\ 1461.4663 & 1481.9420 \\ 1487.3870 & 1490.2166 \\ 1500.6808 & 1501.6020 \\ 1522.5859 & 1526.6443 \\ 1576.6559 & 1639.4588 \\ 1677.3200 & 1703.7144 \\ 1780.2033 & 1804.0159 \\ 3041.5288 & 3043.2918 \\ 3080.3223 & 3082.3393 \\ 3094.4864 & 3100.5706 \\ 3137.1709 & 3139.7021 \\ 3149.7589 & 3151.5363 \\ 3156.1803 & 3179.8999 \\ 3214.6194 & 3217.5906 \\ 3246.5922 & 3262.7452\end{array}$

1319.7814

1351.8037

1374.6719

1393.3408

1412.5106

1448.9750

1486.3289

1500.1787

1515.9865

1569.3649

1658.6789

1709.2156

2384.0875

3073.8422

3092.2958

3127.0269

3140.7715

3151.5999

3204.3649

3243.3157

3264.2050

Zero-point correction=

0.455610 (Hartree/Particle)

Thermal correction to Energy=

0.483215

0.484160

Thermal correction to Enthalpy=

0.394558

Thermal correction to Gibbs Free Energy=

$-1737.596789$

Sum of electronic and zero-point Energies=

$-1737.569184$

Sum of electronic and thermal Enthalpies=

$-1737.568240$

Sum of electronic and thermal Free Energies=

$-1737.657842$

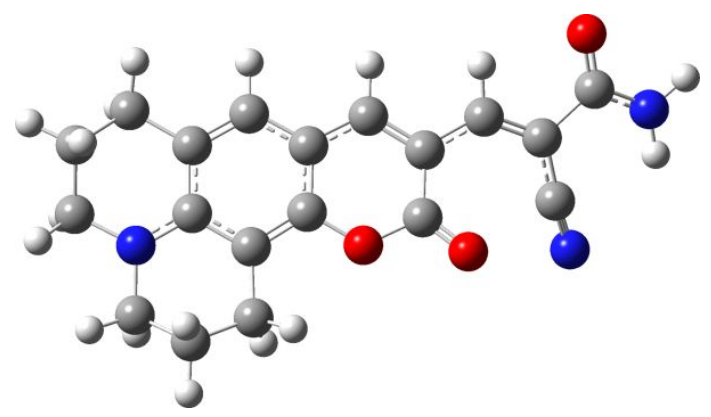

RP-2

Frequencies

20.2394

41.8301

59.4335

64.5888

87.1418

96.0926

105.1321

128.4031

140.4075 


\begin{tabular}{|c|c|c|}
\hline 169.8664 & 174.1399 & 190.9584 \\
\hline 220.4650 & 250.5058 & 266.7896 \\
\hline 275.1780 & 310.3503 & 317.9582 \\
\hline 326.8238 & 358.7679 & 367.0807 \\
\hline 395.7161 & 410.4470 & 435.3745 \\
\hline 438.2083 & 458.7184 & 464.0524 \\
\hline 471.8386 & 520.0515 & 527.5521 \\
\hline 546.7998 & 552.9765 & 563.8334 \\
\hline 574.8223 & 616.8533 & 636.6248 \\
\hline 642.5308 & 650.5812 & 693.1379 \\
\hline 707.5175 & 735.4719 & 746.1472 \\
\hline 770.1208 & 780.9773 & 810.4071 \\
\hline 826.1788 & 869.5696 & 876.3840 \\
\hline 887.5932 & 913.3570 & 927.1632 \\
\hline 929.6708 & 962.1025 & 969.2990 \\
\hline 995.5205 & 1005.6141 & 1042.7648 \\
\hline 1055.3734 & 1076.6669 & 1099.0767 \\
\hline 1105.3370 & 1110.0756 & 1115.2920 \\
\hline 1134.7552 & 1149.3832 & 1192.6261 \\
\hline 1210.9840 & 1218.7439 & 1232.9073 \\
\hline 1238.7377 & 1253.4005 & 1261.3177 \\
\hline 1268.0811 & 1320.6796 & 1324.6375 \\
\hline 1348.2990 & 1354.5812 & 1367.5733 \\
\hline 1384.5645 & 1385.3888 & 1393.5795 \\
\hline 1400.9727 & 1410.1463 & 1415.5744 \\
\hline 1429.1220 & 1431.5821 & 1482.2831 \\
\hline 1484.9742 & 1489.1883 & 1495.0376 \\
\hline 1502.1069 & 1507.3078 & 1513.8329 \\
\hline 1532.6308 & 1573.9322 & 1617.9911 \\
\hline 1634.6898 & 1648.5844 & 1665.2995 \\
\hline 1702.5160 & 1744.9445 & 1797.5805 \\
\hline 2350.5486 & 3059.1934 & 3069.0864 \\
\hline 3071.9116 & 3078.8717 & 3095.3980 \\
\hline 3100.5930 & 3134.0826 & 3139.6132 \\
\hline 3147.5250 & 3150.3127 & 3153.0901 \\
\hline 3156.3933 & 3213.8091 & 3222.4145 \\
\hline 3234.6429 & 3591.3842 & 3711.8877 \\
\hline \multicolumn{2}{|c|}{ Zero-point correction $=$} & 0.337377 (Hartree/Particle) \\
\hline \multicolumn{2}{|c|}{ Thermal correction to Energy= } & 0.358113 \\
\hline \multicolumn{2}{|c|}{ Thermal correction to Enthalpy= } & 0.359058 \\
\hline \multicolumn{2}{|c|}{ Thermal correction to Gibbs Free Energy= } & 0.287350 \\
\hline \multicolumn{2}{|c|}{ Sum of electronic and zero-point Energies $=$} & -1123.449445 \\
\hline \multicolumn{2}{|c|}{ Sum of electronic and thermal Energies $=$} & -1123.428709 \\
\hline
\end{tabular}


Sum of electronic and thermal Enthalpies=

Sum of electronic and thermal Free Energies=

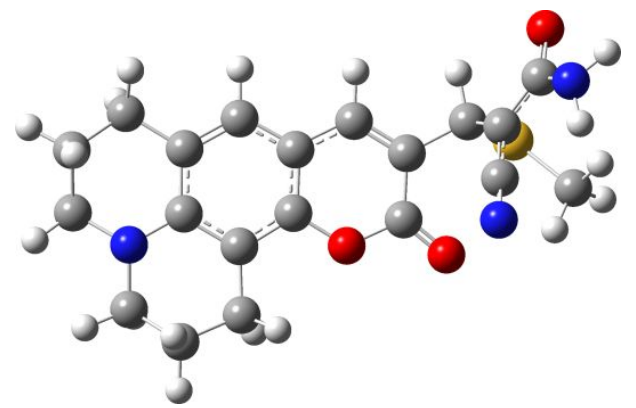

$\left[\mathrm{RP}-2-\mathrm{SCH}_{3}\right]^{-}$

Frequencies

26.9531

66.6434

103.2320

127.6299

165.7420

198.0481

273.6690

323.8874

364.8573

431.5796

460.2062

527.4968

553.7739

583.0271

656.5057

724.6365

759.6928

812.6818

874.5182

921.3452

971.1864

998.8164

1082.3303

1110.3854

1158.9466

1221.6008

1254.5117

1267.4797

1331.1087

1352.6957

1387.6830
$-1123.427764$

$-1123.499472$
40.1270

85.7646

114.2780

152.4650

188.5128

231.2195

297.1390

354.9647

418.7490

448.2939

486.6360

539.5765

580.0464

642.2732

690.9821

741.9074

798.1199

868.1076

912.2797

961.3570

992.7065

1055.4094

1109.6022

1131.9482

1207.1383

1239.6782

1262.9119

1316.3666

1351.5772

1372.5573

1400.5853 


1405.5920
1435.1994
1489.2206
1505.5874
1522.4005
1613.1524
1684.4966
2245.1151
3075.0639
3094.7204
3131.3632
3147.6009
3182.9008
3209.5167

Zero-point correction $=$

Thermal correction to Energy=

Thermal correction to Enthalpy=

Thermal correction to Gibbs Free Energy=

Sum of electronic and zero-point Energies=

Sum of electronic and thermal Energies $=$

Sum of electronic and thermal Enthalpies=

Sum of electronic and thermal Free Energies=

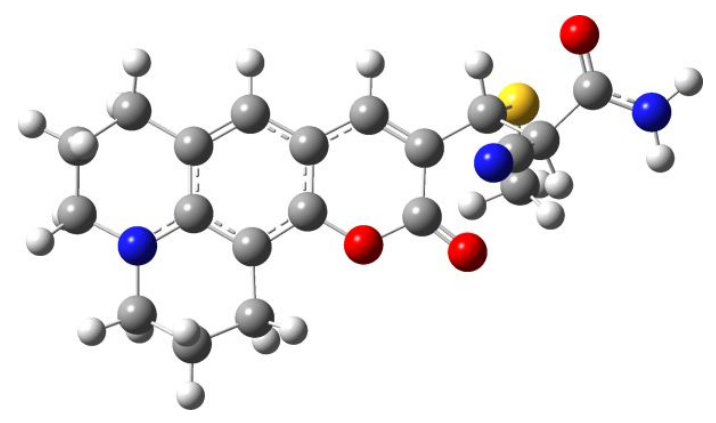

1419.9866

1475.2322

1494.5976

1516.3568

1569.5408

1645.4783

1787.5116

3038.5596

3093.4038

3131.1389

3140.6997

3151.9301

3203.5691

3675.4231

0.377599 (Hartree/Particle)
0.401611
0.402555
0.323646
-1561.586142
-1561.562131
-1561.561186
-1561.640096

RP-2-SCH

Frequencies

27.9395

44.9164

52.6691

58.7054

69.8427

75.9394

93.4649

99.8707

107.8697

124.7378

143.2142

145.9283

158.3309

176.3019

181.3514

202.5508

232.7429

249.1450

256.3878

279.1256

293.8511

322.8800

344.0640

352.6907

367.2091

378.5951

393.7567

412.6174

428.9080

442.3102 


451.7119
487.9347
539.2442
619.2217
659.2140
730.4845
773.6269
823.9250
891.7725
926.1645
985.7204
1008.3635
1052.8104
1107.5917
1132.3699
1210.3122
1236.6196
1257.9507
1316.4011
1333.9619
1374.3421
1393.6527
1423.6309
1480.8990
1490.3219
1505.2310
1527.8913
1639.5296
1764.0658
3047.2558
3072.7680
3100.3704
3134.8892
3153.1975
3192.6023
3218.6442

Zero-point correction $=$

Thermal correction to Energy=

Thermal correction to Enthalpy=

Thermal correction to Gibbs Free Energy=

Sum of electronic and zero-point Energies=

Sum of electronic and thermal Energies=

Sum of electronic and thermal Enthalpies=
475.7544

529.2312

573.3441

643.4631

709.0702

745.4745

812.9616

877.2664

922.0834

959.7787

998.5141

1041.0918

1091.2856

1118.7504

1192.6581

1233.7237

1254.4374

1290.9291

1325.3434

1366.8754

1390.5330

1405.2578

1446.3930

1486.4685

1503.6385

1519.5938

1636.4004

1704.8823

2383.7608

3072.3075

3097.5083

3132.9191

3149.3997

3173.7901

3216.5159

3723.9262

0.391273 (Hartree/Particle)

0.415444

0.416389

0.337372

$-1562.058087$

$-1562.033915$

$-1562.032971$ 


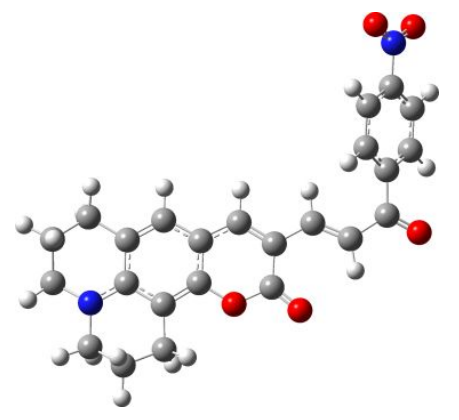

RP-Ph-NO ${ }_{2}$

Frequencies

22.3638

26.3741

37.5230

62.7353

69.7912

74.7944

76.2645

88.7738

108.4796

110.9724

131.4101

154.9982

169.3033

174.4706

200.6499

202.6085

232.9760

261.3929

290.9438

293.1264

304.7907

322.2353

327.1226

355.5584

366.7387

393.3377

406.0800

419.0229

425.5738

438.1435

450.0728

462.2476

471.4552

492.8814

525.8163

526.6119

538.9333

557.7961

568.6842

603.3310

616.9201

637.3907

643.7927

654.4314

690.1832

693.6555

722.2879

733.8785

738.1385

757.9839

772.5704

786.7628

799.8833

815.7314

867.4376

871.5812

874.9363

891.3201

892.1146

899.2642

910.2602

916.9333

922.3524

930.6536

965.5388

984.1876

996.7085

1035.1028

1013.1914

1021.1458

1040.4781

1041.1145

1055.5739

1082.0344

1104.4078

1109.9690

1112.8644

1127.5370

1135.2176

1146.6810

1157.0482

1191.0579

1209.6324

1212.2233

1219.5451

1229.7943

1241.4898

1251.8757

1263.3584

1264.5945

1288.7056

1310.7472

1318.2918

1326.6391

1335.7181

1348.6907 


1353.5256
1377.7020
1402.3662
1426.7957
1481.9322
1499.5673
1517.1875
1572.5959
1656.3185
1700.6676
1785.3595
3073.9349
3104.0315
3143.2409
3155.3460
3220.9763
3278.3041

Zero-point correction $=$

Thermal correction to Energy=

Thermal correction to Enthalpy=

Thermal correction to Gibbs Free Energy=

Sum of electronic and zero-point Energies=

Sum of electronic and thermal Energies=

Sum of electronic and thermal Enthalpies=

Sum of electronic and thermal Free Energies=

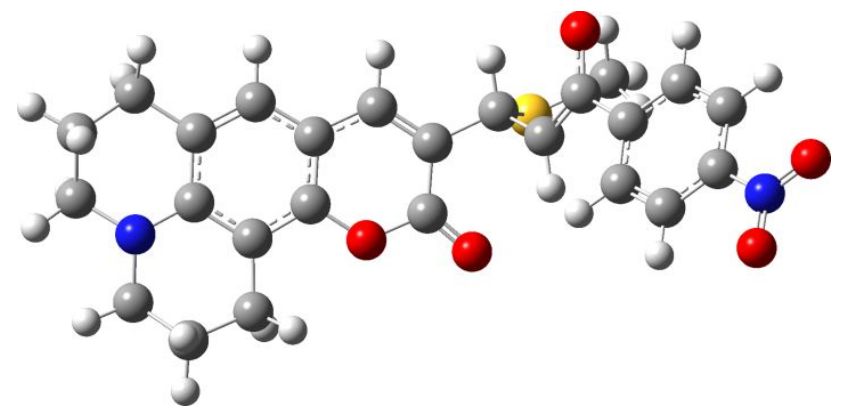

[RP-Ph- $\left.\mathrm{NO}_{2}-\mathrm{SCH}_{3}\right]^{-}$

Frequencies

14.5485
46.9589
76.1775
94.5268
116.9247
174.6698
235.1272

14.5485

29.9773

57.7059

80.5061

103.6771

137.7759

180.3641

236.0879
1371.0685

1394.5853

1425.0710

1479.4078

1487.5919

1508.0376

1555.0922

1651.8350

1697.6408

1730.2922

3058.0238

3097.2992

3136.4596

3151.7004

3213.7501

3265.7359

3291.4299

0.406696 (Hartree/Particle)

0.431393

0.432337

0.350806

$-1411.191262$

$-1411.166566$

$-1411.165622$

$-1411.247152$
37.0870

63.8906

91.1697

112.8618

170.8467

193.6703

253.6881 


\begin{tabular}{|c|c|c|}
\hline 263.5512 & 279.3910 & 292.9488 \\
\hline 302.6028 & 310.4312 & 320.2838 \\
\hline 352.1759 & 364.8790 & 390.2783 \\
\hline 396.1848 & 414.2520 & 420.7792 \\
\hline 431.8472 & 444.9809 & 457.3818 \\
\hline 470.2821 & 476.3648 & 508.4039 \\
\hline 526.4438 & 528.1331 & 534.5222 \\
\hline 554.2261 & 566.6436 & 576.3519 \\
\hline 624.5009 & 638.1819 & 644.2944 \\
\hline 655.5641 & 683.5900 & 690.1636 \\
\hline 694.0063 & 708.3964 & 730.4534 \\
\hline 741.1661 & 746.1748 & 750.9827 \\
\hline 759.5290 & 791.6752 & 804.2470 \\
\hline 810.3002 & 864.3736 & 867.3094 \\
\hline 872.6005 & 874.6421 & 894.6902 \\
\hline 901.4977 & 902.9074 & 913.7352 \\
\hline 924.8562 & 929.4806 & 962.2738 \\
\hline 975.8852 & 987.8931 & 994.7357 \\
\hline 1014.0050 & 1015.5706 & 1020.6160 \\
\hline 1029.6016 & 1041.1027 & 1052.7538 \\
\hline 1081.0751 & 1089.5557 & 1106.2567 \\
\hline 1111.4590 & 1120.7113 & 1132.2024 \\
\hline 1132.9918 & 1153.6247 & 1164.9362 \\
\hline 1189.4123 & 1207.0680 & 1210.4990 \\
\hline 1220.2564 & 1228.8333 & 1232.5320 \\
\hline 1238.9787 & 1256.0544 & 1260.6918 \\
\hline 1262.8545 & 1270.9709 & 1311.1975 \\
\hline 1314.2790 & 1318.8788 & 1323.1718 \\
\hline 1332.1078 & 1349.4740 & 1371.7545 \\
\hline 1376.0873 & 1380.1182 & 1386.0862 \\
\hline 1391.3134 & 1399.4467 & 1403.5502 \\
\hline 1415.6517 & 1421.6038 & 1444.4075 \\
\hline 1451.8272 & 1472.3718 & 1478.2534 \\
\hline 1484.4294 & 1486.2111 & 1487.2459 \\
\hline 1500.1289 & 1504.5626 & 1505.5611 \\
\hline 1514.4950 & 1518.2717 & 1525.2890 \\
\hline 1543.8601 & 1566.2442 & 1619.4929 \\
\hline 1638.9804 & 1646.1436 & 1679.5099 \\
\hline 1684.7808 & 1695.9066 & 1711.6374 \\
\hline 1775.3405 & 3032.6946 & 3038.3312 \\
\hline 3072.2873 & 3073.1863 & 3090.1032 \\
\hline 3095.6627 & 3097.0196 & 3128.7563 \\
\hline 3129.5278 & 3132.6034 & 3138.4088 \\
\hline 3141.9801 & 3148.6610 & 3150.7245 \\
\hline
\end{tabular}




\begin{tabular}{|c|c|c|}
\hline 3184.2272 & 3187.3112 & 3211.6389 \\
\hline 3213.4360 & 3251.6138 & 3259.1054 \\
\hline 3263.0172 & 3273.8829 & 3280.4452 \\
\hline \multicolumn{2}{|c|}{ Zero-point correction $=$} & 0.446294 (Hartree/Particle) \\
\hline \multicolumn{2}{|c|}{ Thermal correction to Energy= } & 0.474344 \\
\hline \multicolumn{2}{|c|}{ Thermal correction to Enthalpy= } & 0.475288 \\
\hline \multicolumn{2}{|c|}{ Thermal correction to Gibbs Free Energy= } & 0.386010 \\
\hline \multicolumn{2}{|c|}{ Sum of electronic and zero-point Energies $=$} & -1849.321937 \\
\hline \multicolumn{2}{|c|}{ Sum of electronic and thermal Energies $=$} & -1849.293888 \\
\hline \multicolumn{2}{|c|}{ Sum of electronic and thermal Enthalpies $=$} & -1849.292944 \\
\hline Sum of elec & mal Free Energies $=$ & -1849.382222 \\
\hline
\end{tabular}

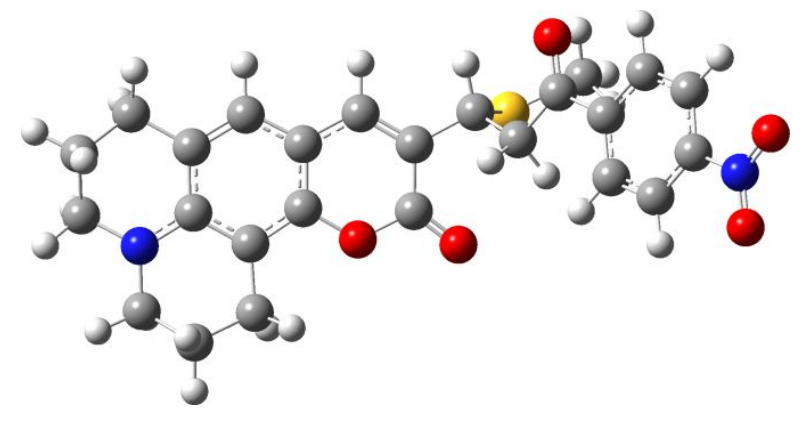

RP-Ph- $\mathrm{NO}_{2}-\mathrm{SCH}_{3}$

Frequencies

$\begin{array}{lcc}14.1002 & 28.4547 & 34.9960 \\ 45.4327 & 52.1451 & 63.3774 \\ 75.0399 & 86.1430 & 88.1970 \\ 94.0680 & 106.2332 & 114.6209 \\ 127.3647 & 136.2188 & 162.2357 \\ 170.8028 & 180.8488 & 194.7289 \\ 229.6077 & 244.3784 & 251.4502 \\ 259.6042 & 288.2470 & 291.4103 \\ 297.8135 & 316.7051 & 330.5654 \\ 349.7897 & 370.2188 & 380.6265 \\ 397.5625 & 413.4573 & 419.9168 \\ 441.1731 & 446.9457 & 448.1641 \\ 460.8833 & 473.4482 & 500.7165 \\ 522.5749 & 528.2992 & 531.1201 \\ 555.5434 & 562.0534 & 566.1648 \\ 576.6000 & 629.4732 & 638.2179 \\ 643.2811 & 683.3919 & 688.6281 \\ 701.1789 & 711.0898 & 735.8591 \\ 745.6682 & 751.5237 & 758.3996 \\ 776.2559 & 802.0006 & 806.8571 \\ 846.1528 & 862.3505 & 873.4371\end{array}$




\begin{tabular}{|c|c|c|}
\hline 881.4815 & 885.2355 & 894.0351 \\
\hline 897.3229 & 917.0713 & 928.6917 \\
\hline 931.0834 & 957.7627 & 969.9342 \\
\hline 985.5233 & 991.8627 & 996.7871 \\
\hline 1002.5480 & 1014.4779 & 1018.4356 \\
\hline 1024.1025 & 1042.2688 & 1044.3400 \\
\hline 1055.3432 & 1082.9484 & 1106.5754 \\
\hline 1110.9749 & 1112.2233 & 1125.8711 \\
\hline 1134.4574 & 1144.3548 & 1157.8240 \\
\hline 1194.0973 & 1201.2803 & 1207.7316 \\
\hline 1220.1227 & 1221.8942 & 1232.4284 \\
\hline 1238.6158 & 1246.4635 & 1256.8437 \\
\hline 1262.6141 & 1267.3002 & 1290.2697 \\
\hline 1317.8101 & 1318.4731 & 1326.5187 \\
\hline 1336.8045 & 1344.5814 & 1354.1994 \\
\hline 1375.0975 & 1380.3905 & 1381.8607 \\
\hline 1387.5943 & 1393.7888 & 1402.2626 \\
\hline 1406.4063 & 1412.3586 & 1419.3032 \\
\hline 1426.8346 & 1452.1080 & 1466.6151 \\
\hline 1480.0163 & 1481.4472 & 1486.6620 \\
\hline 1488.7485 & 1490.3973 & 1500.8077 \\
\hline 1501.7526 & 1503.2416 & 1516.6096 \\
\hline 1522.5890 & 1526.8775 & 1558.1752 \\
\hline 1576.6437 & 1641.3238 & 1657.7444 \\
\hline 1678.8178 & 1694.6771 & 1710.4468 \\
\hline 1714.0660 & 1780.4758 & 1809.1658 \\
\hline 3040.7073 & 3043.9020 & 3075.3760 \\
\hline 3081.2326 & 3082.3783 & 3091.4006 \\
\hline 3095.5781 & 3101.1766 & 3130.3720 \\
\hline 3134.9338 & 3138.7880 & 3142.8847 \\
\hline 3146.6454 & 3152.3074 & 3152.3959 \\
\hline 3156.0542 & 3178.9505 & 3200.6491 \\
\hline 3214.7437 & 3219.7088 & 3252.8079 \\
\hline 3257.3612 & 3271.3591 & 3276.8948 \\
\hline \multicolumn{2}{|c|}{ Zero-point correction $=$} & 0.460188 (Hartree/Particle) \\
\hline \multicolumn{2}{|c|}{ Thermal correction to Energy= } & 0.488283 \\
\hline \multicolumn{2}{|c|}{ Thermal correction to Enthalpy= } & 0.489227 \\
\hline \multicolumn{2}{|c|}{ Thermal correction to Gibbs Free Energy= } & 0.399705 \\
\hline \multicolumn{2}{|c|}{ Sum of electronic and zero-point Energies $=$} & -1849.802570 \\
\hline \multicolumn{2}{|c|}{ Sum of electronic and thermal Energies $=$} & -1849.774476 \\
\hline \multicolumn{2}{|c|}{ Sum of electronic and thermal Enthalpies $=$} & -1849.773531 \\
\hline \multicolumn{2}{|c|}{ Sum of electronic and thermal Free Energies $=$} & -1849.863054 \\
\hline
\end{tabular}




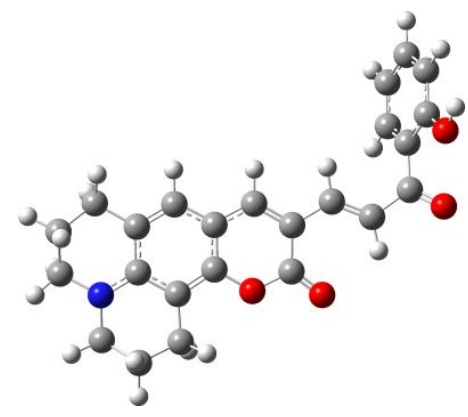

RP-Ph-OH

Frequencies

23.2267

32.7612

38.7764

57.5588

70.6220

93.5231

114.0287

153.5176

159.5793

87.5944

125.0794

195.5847

200.3662

171.9847

244.5992

274.4326

214.1386

303.4088

326.6281

290.3124

362.2451

364.8390

352.7458

406.4837

411.1798

390.7335

434.6226

447.0823

423.8709

463.8205

473.8339

456.6352

527.8006

539.1524

513.6824

546.2108

561.5691

572.9468

606.3234

617.8251

638.8035

648.3545

688.0768

702.2427

714.3144

737.7106

752.5301

756.0569

770.5533

785.7503

799.8470

815.3098

850.2458

868.3157

877.9497

890.3208

894.8807

908.2563

914.0747

933.0717

965.0022

931.2610

992.1085

997.6733

1032.6662

1040.4935

989.2780

1021.5924

1080.4530

1082.8628

1054.9881

1105.1386

1109.3238

1098.1802

1116.2372

1134.2777

1163.0995

1187.4676

1192.7704

1206.0940

1211.1241

1220.4309

1234.2936

1243.0393

1253.7734

1262.7491

1267.2642

1286.0743

1312.2305

1320.0645

1326.3216

1345.7054

1348.1136

1358.2529

1368.7183

1371.9829

1375.9550

1384.8152 


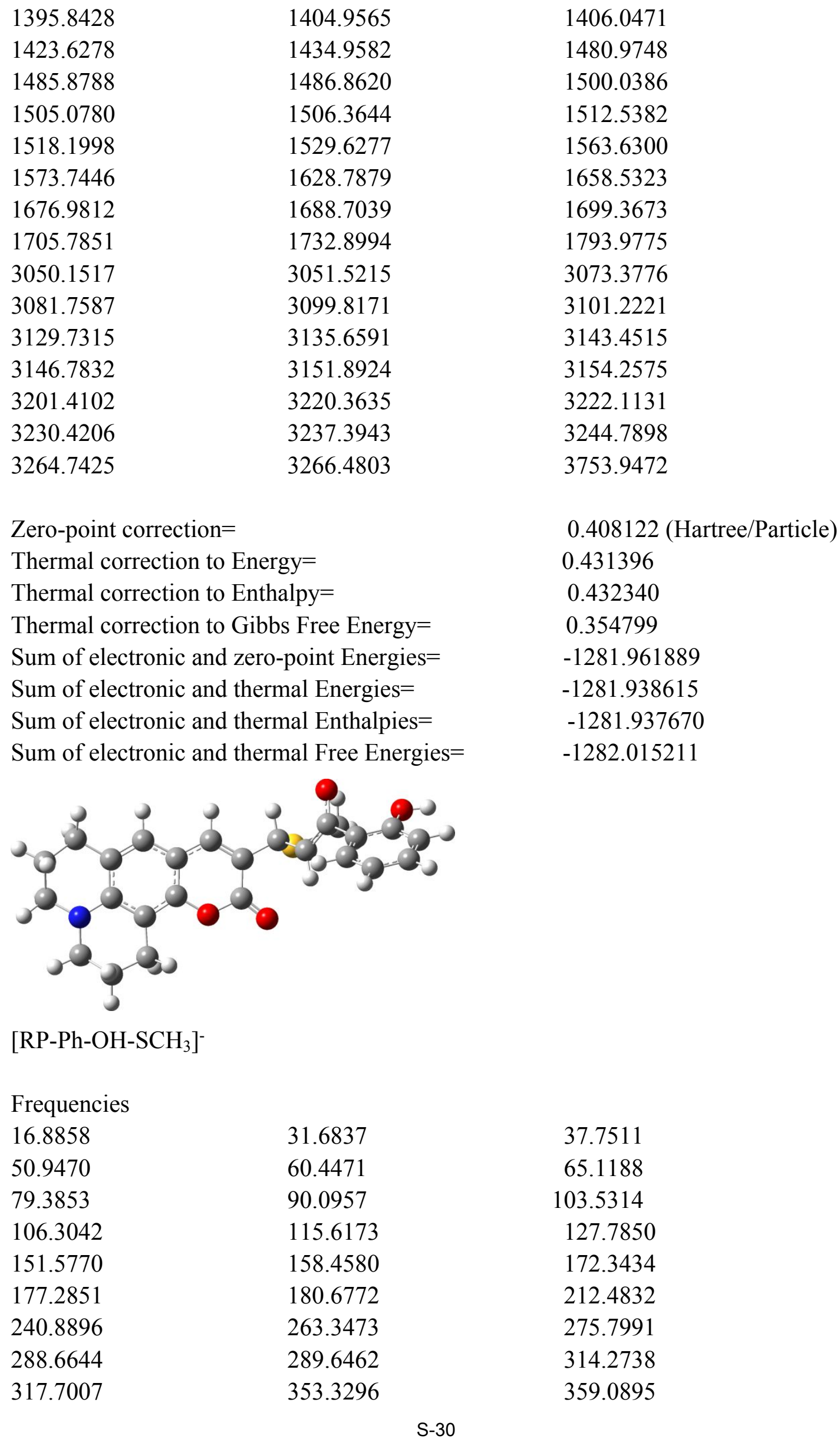




\begin{tabular}{|c|c|c|}
\hline 382.5362 & 395.5633 & 401.2059 \\
\hline 412.5271 & 426.0418 & 439.1580 \\
\hline 448.7255 & 463.5811 & 468.6954 \\
\hline 470.9336 & 519.9538 & 525.6860 \\
\hline 529.1197 & 551.4411 & 560.9035 \\
\hline 572.4187 & 593.5912 & 623.6480 \\
\hline 641.0747 & 649.6970 & 661.0770 \\
\hline 689.9421 & 708.1483 & 711.0149 \\
\hline 729.3702 & 737.6836 & 747.9271 \\
\hline 757.6699 & 775.9570 & 786.7802 \\
\hline 800.1635 & 806.4886 & 834.1321 \\
\hline 863.9133 & 870.3344 & 887.2815 \\
\hline 894.9811 & 897.2828 & 912.3069 \\
\hline 920.9015 & 929.5526 & 960.0490 \\
\hline 971.4406 & 974.0225 & 989.0452 \\
\hline 990.9878 & 1002.5532 & 1008.1590 \\
\hline 1040.1398 & 1052.5024 & 1076.2513 \\
\hline 1083.9583 & 1087.5899 & 1105.3814 \\
\hline 1107.7305 & 1113.2696 & 1127.8888 \\
\hline 1134.6491 & 1167.3942 & 1173.4240 \\
\hline 1189.0292 & 1203.0223 & 1205.3115 \\
\hline 1216.4689 & 1219.4573 & 1233.5742 \\
\hline 1238.4565 & 1250.9115 & 1255.4510 \\
\hline 1257.0426 & 1267.3947 & 1287.7096 \\
\hline 1306.6765 & 1311.8010 & 1325.5902 \\
\hline 1326.5943 & 1331.2715 & 1348.1651 \\
\hline 1369.0530 & 1373.8770 & 1378.6524 \\
\hline 1385.5336 & 1392.3608 & 1399.8021 \\
\hline 1402.5944 & 1417.2390 & 1418.3134 \\
\hline 1456.3436 & 1471.2392 & 1474.4935 \\
\hline 1484.5830 & 1485.7474 & 1498.4026 \\
\hline 1499.8655 & 1502.2647 & 1508.8326 \\
\hline 1514.3077 & 1517.9879 & 1523.5006 \\
\hline 1554.7476 & 1563.2322 & 1614.2339 \\
\hline 1642.1537 & 1675.1958 & 1682.1713 \\
\hline 1696.6429 & 1707.0787 & 1778.0016 \\
\hline 3031.5934 & 3032.7951 & 3074.3075 \\
\hline 3074.6496 & 3089.3924 & 3099.1062 \\
\hline 3099.5898 & 3127.7530 & 3130.3449 \\
\hline 3131.7168 & 3136.3658 & 3147.0990 \\
\hline 3150.4932 & 3153.8755 & 3182.7721 \\
\hline 3188.0717 & 3207.4472 & 3210.6516 \\
\hline 3217.7690 & 3229.3357 & 3233.1673 \\
\hline 3245.6592 & 3252.2613 & 3781.4906 \\
\hline
\end{tabular}


Zero-point correction=

Thermal correction to Energy=

Thermal correction to Enthalpy=

Thermal correction to Gibbs Free Energy=

Sum of electronic and zero-point Energies=

Sum of electronic and thermal Energies=

Sum of electronic and thermal Enthalpies=

Sum of electronic and thermal Free Energies=

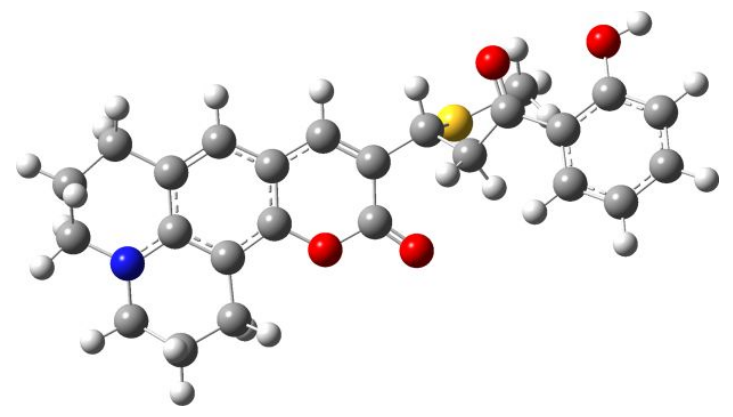

0.446970 (Hartree/Particle)

0.473867

0.474811

0.388839

$-1720.085524$

$-1720.058627$

$-1720.057683$

$-1720.143655$

$\mathrm{RP}-\mathrm{Ph}-\mathrm{OH}-\mathrm{SCH}_{3}$

Frequencies

21.9351

52.4709

84.1402

107.6322

156.7472

181.2270

250.2107

286.3426

321.2872

386.2523

422.2128

445.0008

471.4711

529.5094

572.3745

628.6566

681.2020

735.8512

762.8303

804.4139

868.2918

898.1741

929.7675

979.2727
25.9994

58.2734

91.5185

112.6378

161.2344

208.3669

255.2922

294.3881

349.6354

402.6877

430.5577

453.6650

511.4061

538.3779

580.0721

639.5849

700.1527

740.6307

786.3982

831.8193

878.3692

912.4595

956.1987

988.3877
37.2236

76.2019

105.1702

131.4964

163.0909

232.9283

283.2057

315.2759

365.6312

412.2738

437.0235

465.9067

525.6732

559.3374

595.0990

660.5643

717.9795

750.1504

797.3776

858.2299

894.7783

922.0140

966.4414

993.9035 


\begin{tabular}{|c|c|c|}
\hline 995.1658 & 1000.6847 & 1016.9887 \\
\hline 1020.2806 & 1041.8699 & 1052.5640 \\
\hline 1081.1525 & 1093.0076 & 1096.4467 \\
\hline 1106.5015 & 1111.9718 & 1122.2844 \\
\hline 1133.4270 & 1149.8817 & 1184.3635 \\
\hline 1190.0472 & 1192.7195 & 1208.6292 \\
\hline 1209.7446 & 1221.6342 & 1232.8232 \\
\hline 1237.9639 & 1250.9933 & 1255.0635 \\
\hline 1261.2377 & 1264.7950 & 1286.1208 \\
\hline 1290.2307 & 1316.6249 & 1320.2070 \\
\hline 1322.6180 & 1334.5722 & 1350.6094 \\
\hline 1355.0402 & 1372.7756 & 1373.4645 \\
\hline 1384.8345 & 1384.9483 & 1392.0121 \\
\hline 1397.6845 & 1403.3191 & 1408.1162 \\
\hline 1418.5275 & 1427.6805 & 1460.4212 \\
\hline 1476.5168 & 1479.1022 & 1486.1263 \\
\hline 1487.2863 & 1496.8262 & 1501.9062 \\
\hline 1503.4398 & 1506.4734 & 1514.9623 \\
\hline 1519.0200 & 1526.1471 & 1564.3759 \\
\hline 1575.8366 & 1639.5994 & 1676.5943 \\
\hline 1677.1036 & 1700.3328 & 1708.9720 \\
\hline 1774.7929 & 1786.8035 & 3044.6508 \\
\hline 3044.8777 & 3071.4446 & 3075.2744 \\
\hline 3076.1350 & 3091.0860 & 3091.2272 \\
\hline 3093.6505 & 3129.9915 & 3134.4094 \\
\hline 3140.4809 & 3141.2793 & 3144.5136 \\
\hline 3149.3350 & 3150.5358 & 3171.7862 \\
\hline 3181.2069 & 3197.9292 & 3214.4185 \\
\hline 3217.1756 & 3227.3539 & 3236.5055 \\
\hline 3243.1309 & 3252.6279 & 3758.4756 \\
\hline \multicolumn{2}{|c|}{ Zero-point correction $=$} & 0.461024 (Hartree/Particle) \\
\hline \multicolumn{2}{|c|}{ Thermal correction to Energy= } & 0.487790 \\
\hline \multicolumn{2}{|c|}{ Thermal correction to Enthalpy= } & 0.488734 \\
\hline \multicolumn{2}{|c|}{ Thermal correction to Gibbs Free Energy= } & 0.403335 \\
\hline \multicolumn{2}{|c|}{ Sum of electronic and zero-point Energies $=$} & -1720.573560 \\
\hline \multicolumn{2}{|c|}{ Sum of electronic and thermal Energies $=$} & -1720.546794 \\
\hline \multicolumn{2}{|c|}{ Sum of electronic and thermal Enthalpies $=$} & -1720.545850 \\
\hline \multicolumn{2}{|c|}{ Sum of electronic and thermal Free Energies $=$} & -1720.631249 \\
\hline
\end{tabular}




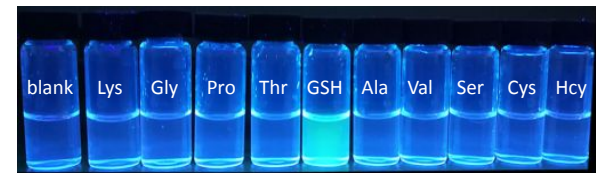

Figure S19. The photo of RP-2 reaction with different amino acids under UV irradiation at $365 \mathrm{~nm}$.

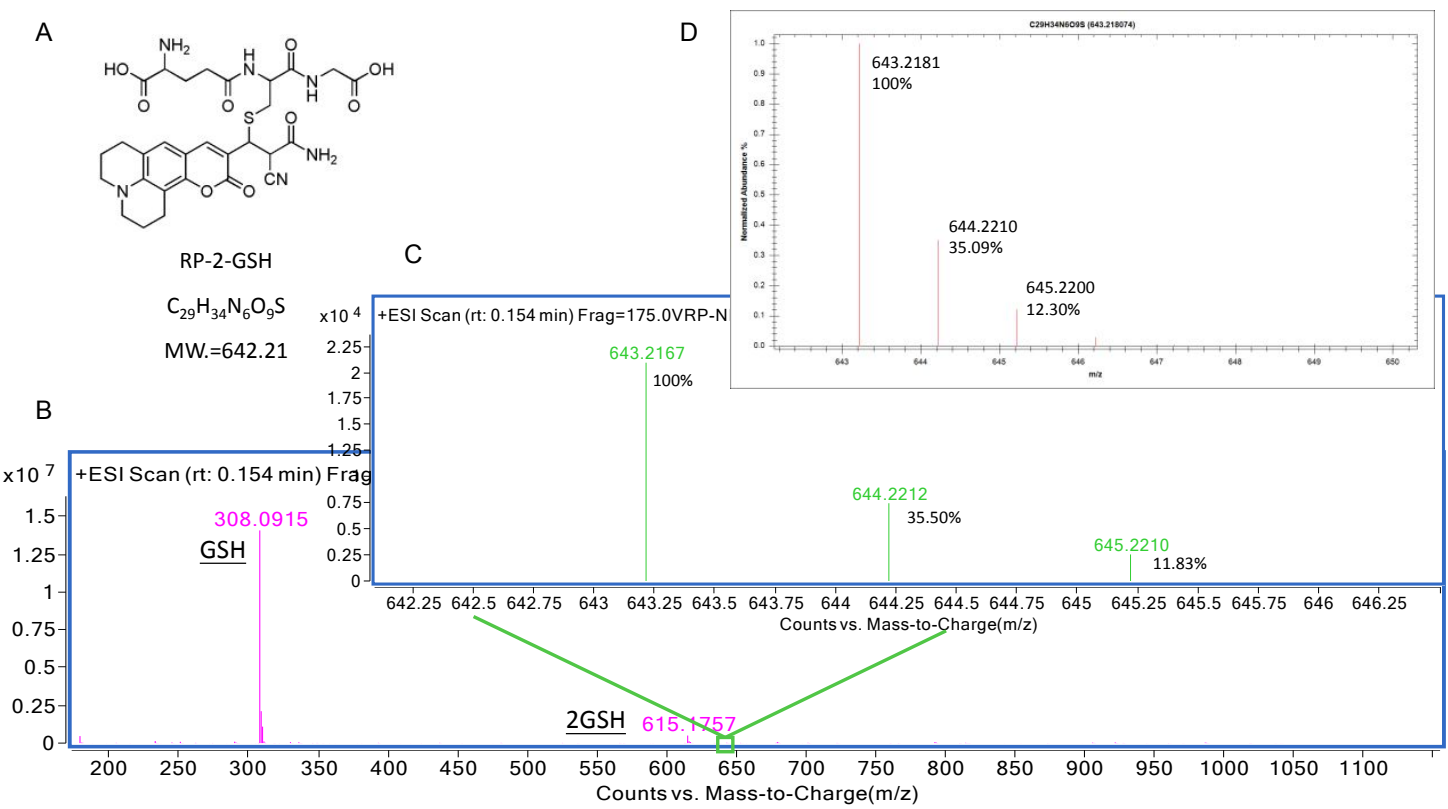

Figure S20. (A) The chemical structure of adduct, RP-2-GSH. (B) ESI-MS of the RP-2 reaction with an excess of GSH in methanol. (C) An enlarged view of (B) with $\mathrm{m} / \mathrm{z}$ from 642.25 to 646.25 . (D) Isotope distribution and corresponding relative contents of RP-2-GSH $(\mathrm{M}+\mathrm{H})$ simulated by isotope distribution calculator. 

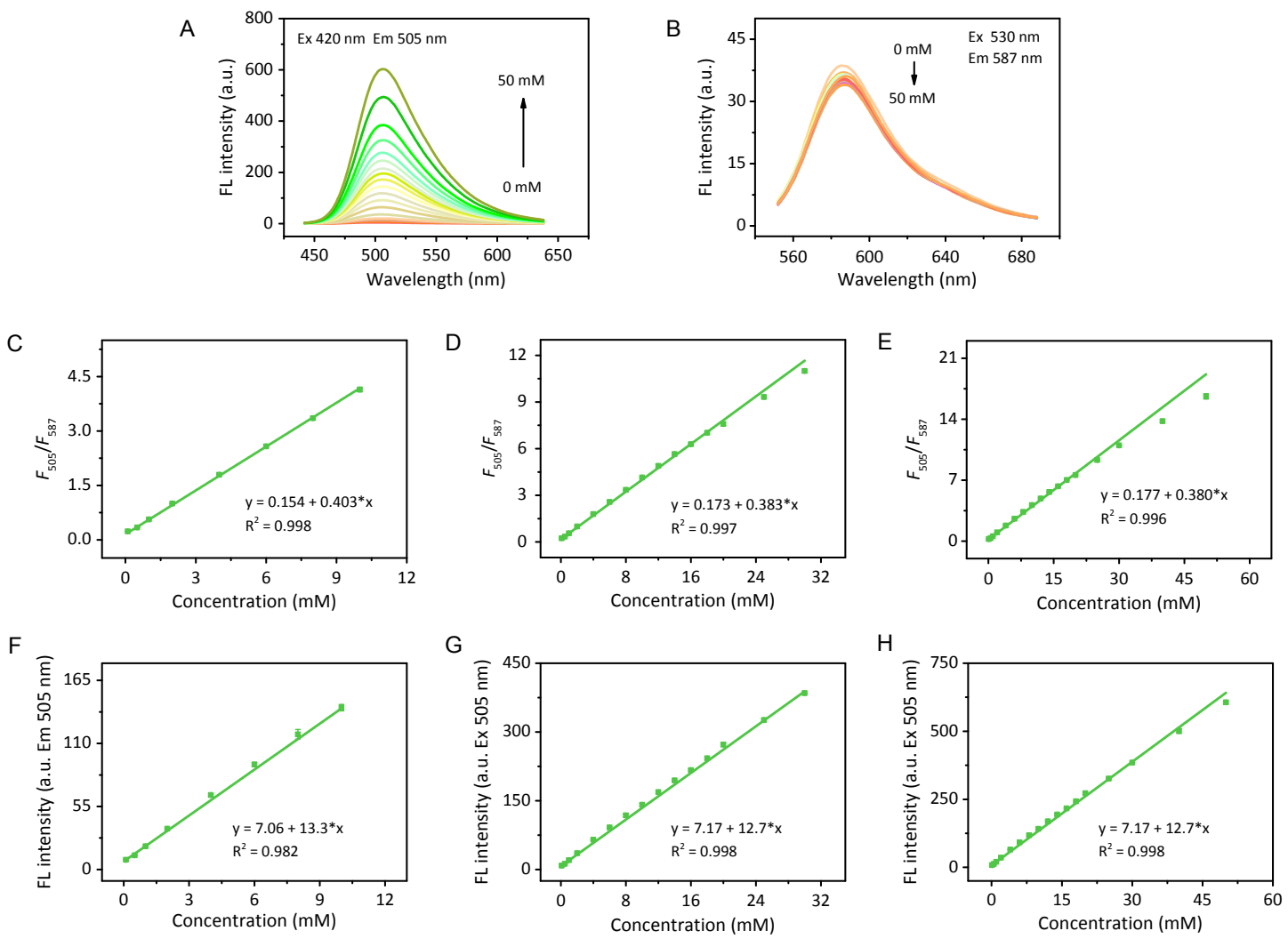

Figure S21. FL spectra of RP-2 $(2.5 \mu \mathrm{M})$ with increasing concentration of GSH $(0.1-50 \mathrm{mM})$ at $(\mathrm{A}) \lambda_{\mathrm{ex}}=420 \mathrm{~nm}$ and (B) $\lambda_{\mathrm{ex}}=530 \mathrm{~nm}$ in the PBS buffer. The FL ratios $\left(F_{505} / F_{587}\right)$ and $\mathrm{FL}$ intensity at $505 \mathrm{~nm}\left(F_{505}\right)$, respectively, were linearly fitted with a concentration of GSH range 0.1 to $10 \mathrm{mM}(\mathrm{C}, \mathrm{F}), 30 \mathrm{mM}(\mathrm{D}, \mathrm{G})$ and $50 \mathrm{mM}$ $(E, H)$. Each data point represents the mean of three independent experiments. 


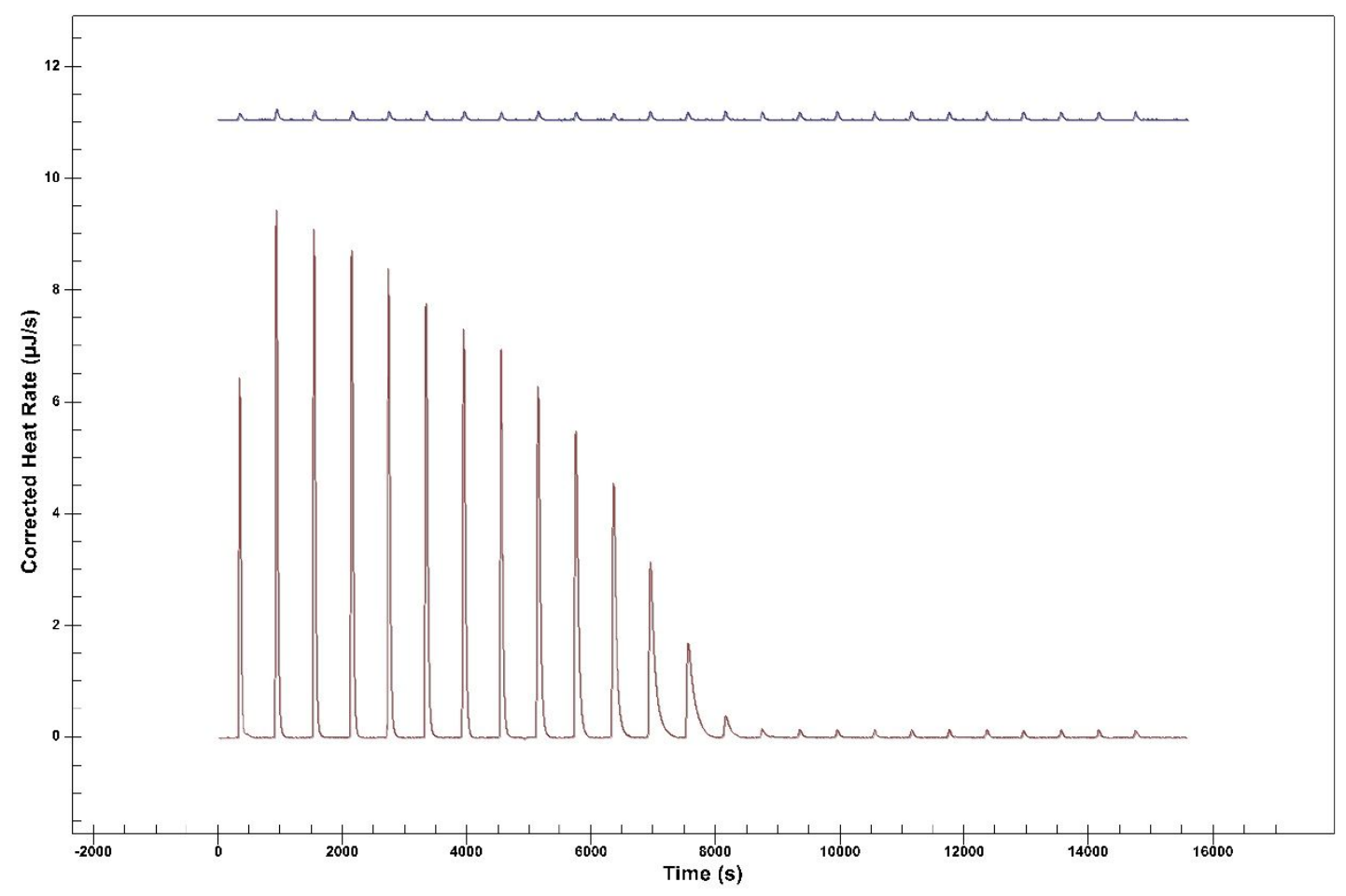

Figure S22. ITC titration curves of NEM into GSH (red line) and NEM into solvent of GSH (blue line). Both solvents are PBS buffer containing 1\% DMSO.

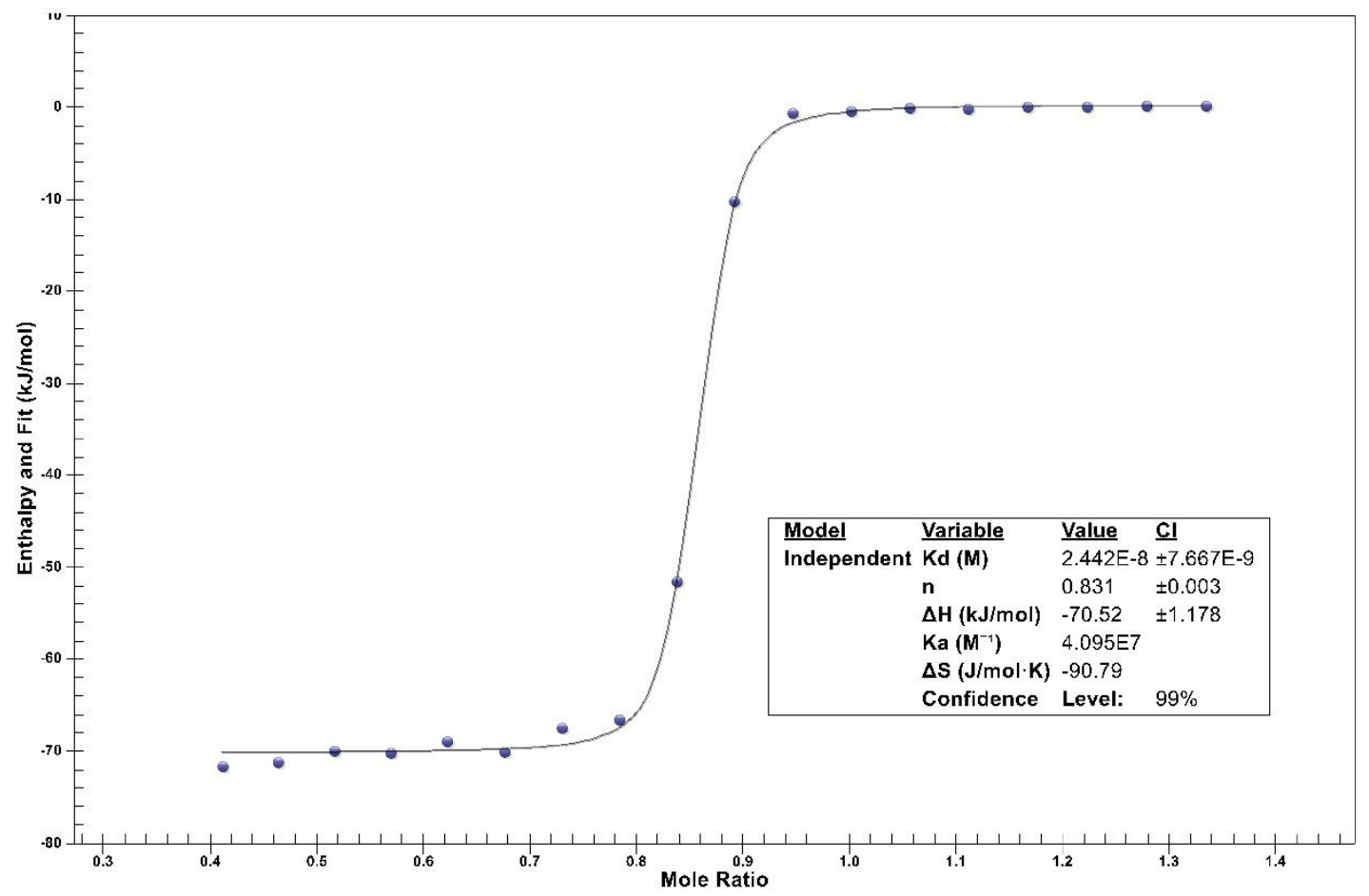

Figure S23. The fitting curve by independent model for nonspecific binding and the thermodynamic parameters calculated by built-in software of ITC. 

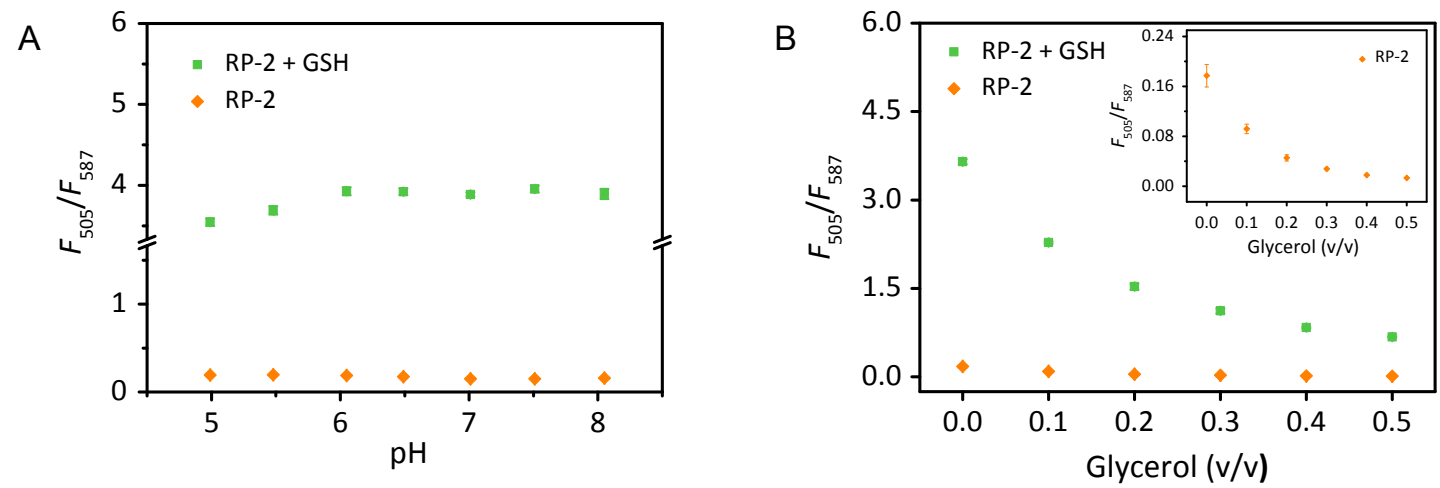

Figure S24. The FL intensity ratios $F_{505} / F_{587}$ of RP-2 and RP-2-GSH under different pH (A) and viscosity (B) conditions. Each data point represents the mean of three independent experiments. $\lambda_{\mathrm{ex}}=420 \mathrm{~nm}, \lambda_{\mathrm{em}}=505 \mathrm{~nm} ; \lambda_{\mathrm{ex}}=530 \mathrm{~nm}, \lambda_{\mathrm{em}}=587 \mathrm{~nm}$.

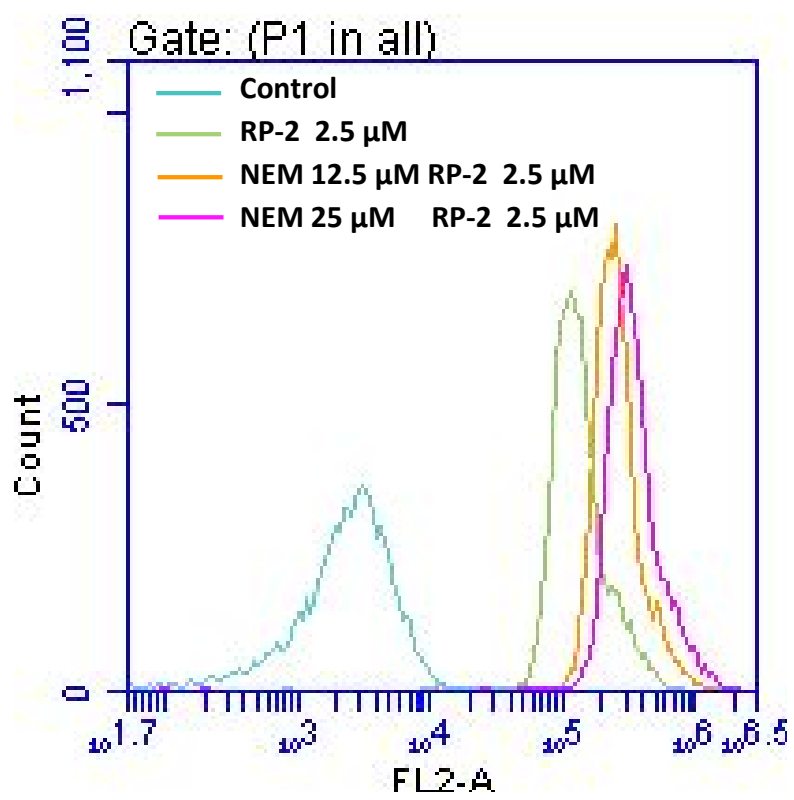

Figure S25. Flow cytometric analysis of HeLa cells stained with control (sky-blue line), RP-2 (2.5 $\mu \mathrm{M}$, green line), RP-2 after treatment with $12.5 \mu \mathrm{M}$ of NEM (orange line) and $25 \mu \mathrm{M}$ of NEM (rose line). 
Table S2. The codes designed in MATLAB.

img = imread('xx.jpg');

\%img = rgb2gray (img_rgb);

\%img =imbinarize(img,'global');

\%figure,imshow(img);

img_bw_2 $=$ im2 $\mathrm{bw}(\mathrm{img}, 0.5) ; \quad \%$ mark

\%figure,imshow(img_bw_2);

$\%$ auto = graythresh(img);

img_bw_1 = im2bw(img,0.09);

\%figure,imshow(img_bw_1);

$a=$ img_bw_1-img_bw_2;

figure,imshow(a);

$\mathrm{a}=\operatorname{uint} 8(\mathrm{a})$

$\mathrm{r}=\operatorname{img}(:,:, 1)$

$\mathrm{g}=\operatorname{img}(:,:, 2)$;

$\mathrm{b}=\operatorname{img}(:,:, 3)$;

$\mathrm{r} 1=\mathrm{r} \cdot{ }^{*} \mathrm{a}$

$\mathrm{g} 1=\mathrm{g} \cdot{ }^{*} \mathrm{a} ;$

$\mathrm{b} 1=\mathrm{b} . * \mathrm{a}$

$\mathrm{p}(:,:, 1)=\mathrm{r} 1$;

$\mathrm{p}(:,:, 2)=\mathrm{g} 1$;

$\mathrm{p}(:,:, 3)=\mathrm{b} 1$; 
$\%$ p_hsv $=\operatorname{rgb} 2 \mathrm{hsv}(\mathrm{p})$;

$\mathrm{m}_{-} \mathrm{h}=\operatorname{mean}(\operatorname{mean}(\mathrm{p}(:,:, 1)))$;

m_s $=$ mean $(\operatorname{mean}(\mathrm{p}(:,:, 2)))$;

$\mathrm{m}_{-} \mathrm{v}=\operatorname{mean}(\operatorname{mean}(\mathrm{p}(:,:, 3)))$;

$\operatorname{disp}\left(m_{-} h\right)$

$\operatorname{disp}\left(\mathrm{m}_{-} \mathrm{s}\right)$;

$\operatorname{disp}\left(\mathrm{m}_{-} \mathrm{v}\right)$;

\%print('done!');

$\% \%$ level=graythresh(f);clear

$\%$ bw2=im2bw(f,0.09); \% label index

$\%$ imshow(bw2);

$\%[\mathrm{~B}, \mathrm{~L}]=$ bwboundaries(img);

$\%$ figure,imshow(img);

$\%$ hold on;

$\%$ for $\mathrm{k}=1$ :length(B)

$\% \quad$ boundary $=\mathrm{B}\{\mathrm{k}\}$;

$\% \quad \operatorname{plot}($ boundary(:,2),boundary(:,1),'g','LineWidth',2);

$\%$ end

$\%$

$\%[\mathrm{~L}, \mathrm{~N}]=$ bwlabel(bw2);

\% img_rgb = label2rgb(L,'hsv',[.5 .5 .5],'shuffle');

$\%$ figure,imshow(img_rgb); hold on

$\%$ for $\mathrm{k}=1:$ length(B) 
$\% \quad$ boundary $=\mathrm{B}\{\mathrm{k}\}$;

$\% \quad \operatorname{plot}($ boundary(:,2), boundary(:,1),'w','LineWidth',2);

$\% \quad$ text(boundary(1,2)-11,boundary(1,1)+11,num2str(k),'Color','y','Fontsize',14, 'FontWeight','bold');

$\%$ end

\section{Supplementary references}

(1) Tian, M.; Yang, M.; Liu, Y.; Jiang, F. L. Rapid and Reversible Reaction-Based Ratiometric Fluorescent Probe for Imaging of Different Glutathione Levels in Living Cells. ACS Appl. Bio Mater. 2019, 2, 4503-4514.

(2) Yuan, L.; Lin, W.; Song, J.; Yang, Y. Development of an ICT-based ratiometric fluorescent hypochlorite probe suitable for living cell imaging. Chem. Commun. 2011, 47, 12691-12693.

(3) Jiang, X.; Yu, Y.; Chen, J.; Zhao, M.; Chen, H.; Song, X.; Matzu, A. J.; Carroll, S. L.; Tan, X.; Sizovs, A.; Cheng, N.; Wang, J. Quantitative Imaging of Glutathione in Live Cells using a Reversible Reaction-Based Ratiometric Fluorescent Probe. ACS Chem. Biol. 2015, 10, 864-874.

(4) Yang, Y.; Bai, B.; Xu, W.; Xu, Z.; Zhang, J.; Li, W. A Highly Sensitive Fluorescent Probe for the Detection of Bisulfite Ion and its Application in Living Cells. Dyes Pigments 2017, 136, 830-835. 